\title{
Modelling of supply and demand-side determinants of liquefied petroleum gas consumption in peri-urban Cameroon, Ghana and Kenya
}

\author{
Matthew Shupler ${ }^{1 凶}$, Judith Mangeni ${ }^{2}$, Theresa Tawiah ${ }^{3}$, Edna Sang ${ }^{2}$, Miranda Baame ${ }^{4}$ \\ Rachel Anderson de Cuevas ${ }^{1}$, Emily Nix ${ }^{10}$, Emmanuel Betang ${ }^{4}$, Jason Saah ${ }^{3}$, Mieks Twumasi ${ }^{3}$, \\ Seeba Amenga-Etego ${ }^{3}$, Reginald Quansah5 ${ }^{5}$, Elisa Puzzolo ${ }^{1,6}$, Bertrand Mbatchou ${ }^{4}$, \\ Kwaku Poku Asante ${ }^{3}$, Diana Menya ${ }^{2}$ and Daniel Pope ${ }^{1}$
}

\begin{abstract}
Household transitions to cleaner cooking fuels (for example, liquefied petroleum gas (LPG)) have historically been studied from a demand perspective, with clean energy usage expected to increase with improvements in household socio-economic status. Although recent studies demonstrate the importance of supply-side determinants in increasing clean cooking, few large-scale studies have assessed their importance quantitatively, relative to demand-related factors. Here, as part of the CLEAN-Air(Africa) study, we examine a population-based survey $(n=5,638)$ of cooking practices in peri-urban communities within Cameroon, Kenya and Ghana. Multilevel logistic and log-linear regression assessed the demand and supply-side determinants of LPG usage (primary versus secondary fuel) and consumption (kilograms per capita per year), respectively. Supply-side factors (for example, cylinder refill and transportation costs) and the use of single versus multiburner stoves were better predictors than household socio-economic status for both the probability of primarily cooking with LPG and the annual LPG consumption. These results highlight the need for policies that promote LPG supply and stove equipment to meet household needs.
\end{abstract}

\section{P} olluting fuels, which include biomass (for example, wood and charcoal), coal and kerosene, are used by approximately 3.8 billion individuals worldwide for cooking, heating and lighting $^{1}$. Household air pollution generated from incomplete combustion of these fuels results in levels of $2.5 \mu \mathrm{m}$ fine particulate matter $\left(\mathrm{PM}_{2.5}\right)$ typically well above World Health Organization (WHO) guidelines ${ }^{2}$. Exposure to $\mathrm{PM}_{2.5}$ in household air pollution is causally associated with many adverse health outcomes, which include cardiopulmonary and respiratory diseases ${ }^{3-6}$. Although fuels such as coal and charcoal generally emit lower levels of $\mathrm{PM}_{2.5}$ than other polluting fuels ${ }^{7}$, their combustion also generates high levels of carbon monoxide, which has been linked to increased blood pressure $^{8}$ and adverse pregnancy outcomes ${ }^{9}$. Additionally, household air pollution contains short-term climate-forcing pollutants, which include black carbon, which is also associated with negative health impacts ${ }^{10}$. It is estimated that $25 \%$ of global anthropogenic black-carbon emissions are produced from household biomass combustion $^{11,12}$. The use of polluting cooking fuel further leads to deforestation in certain locations, particularly in East Africa ${ }^{11}$. Women, typically the primary cook, may travel long distances to gather polluting fuels in some settings, which negatively impacts their livelihoods ${ }^{13,14}$.

In Sub-Saharan Africa (SSA), approximately 900 million people cook with polluting fuels ${ }^{15}$. Governments in SSA, which include Cameroon, Ghana and Kenya, plan to expand the population-level use of liquefied petroleum gas (LPG) as a clean cooking solution to an aspirational target of $35-58 \%$ over the next decade ${ }^{16-18}$. LPG, although a fossil fuel, does not emit black carbon and has much lower $\mathrm{PM}_{2.5}$ emissions than polluting fuels ${ }^{7,16,19}$. Using LPG for cooking can also decrease localized deforestation and reduce the time spent gathering and cooking with polluting fuels ${ }^{7,22}$.

Historically, studies focused on the determinants of clean cooking fuel use have emphasized the 'household energy ladder' model, by which improvements in socio-economic status (SES) lead households to transition to modern energy sources ${ }^{21-23}$. In reality, higher income usually does not lead to a complete transition to clean cooking fuels in low- and middle-income countries, as households will probably continue using polluting fuels alongside clean fuels (fuel 'stacking') to meet all cooking needs ${ }^{24}$. For example, studies in India found that resource-poor rural households provided with LPG cooking equipment under the Pradhan Mantri Ujjwala Yojana (PMUY) programme continued to use polluting fuels, which led to less frequent LPG use compared with that of more affluent urban household ${ }^{25,26}$. There are numerous potential causes of fuel stacking, which include taste preferences, high or unstable fuel costs, convenience and cultural norms $\mathrm{s}^{27-29}$. In SSA, studies carried out in Cameroon ${ }^{30,31}$, Tanzania $^{32}$ and Ethiopia $^{33}$ also found supply-related issues to be important determinants of fuel stacking. Multinational modelling studies conducted in SSA found that community-level effects explained a higher amount of variability in cooking fuel choice than household SES characteristics, which suggests that cooking decisions may be largely driven by fuel availability and other supply-related factors that occur at a broader level ${ }^{34,35}$. Although these studies

'Department of Public Health, Policy and Systems, University of Liverpool, Liverpool, UK. ${ }^{2}$ School of Public Health, Moi University, Eldoret, Kenya. ${ }^{3}$ Kintampo Health Research Centre, Kintampo, Ghana. ${ }^{4}$ Douala General Hospital, Douala, Cameroon. ${ }^{5}$ School of Public Health, University of Ghana, Accra,

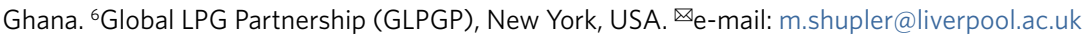


assessed the impact of specific supply and demand-side factors on primary cooking fuel type used, few large-scale studies quantitatively assessed determinants of a higher LPG consumption in SSA. To understand the important drivers of increased LPG consumption, rather than a binary indictor of whether LPG is used, may help uncover strategies that reduce fuel stacking and facilitate a full transition to LPG.

In this study, survey data on cooking behaviours, which include the primary and secondary cooking fuels used and the average annual per capita LPG consumption, were collected in three peri-urban communities in Cameroon, Kenya and Ghana. These countries were specifically chosen as all are implementing policies to scale-up the adoption of LPG for cooking to decrease the negative impacts of polluting cooking fuels on health and the environment (Methods). Multilevel modelling of over 5,500 households from the three countries was conducted in a quantitative assessment of the supply and demand-related impacts on LPG fuel usage in the rapidly urbanising communities of SSA. The modelling results show a significant, positive relationship between increased per capita LPG consumption and lower LPG refill cost, shorter travel time to access the fuel and a higher number of LPG stove burners. Households that indicated a consistent availability of LPG refills at retailers had a significantly higher probability of using LPG as a primary cooking fuel (defined as the fuel used most often (Methods)) than those that reported an inconsistent supply, irrespective of education level and income. This empirical evidence suggests that to enhance LPG accessibility and availability, which includes via expansion of the number of retail points and promotion of multiburner LPG stoves, can be effective short-term interventions to increase the LPG consumption among peri-urban households in SSA.

\section{Cooking environment characteristics}

This study presents findings from the Global Health Research Group on clean energy access for the prevention of non-communicable disease in Africa through clean air (CLEAN-Air(Africa)) programme ${ }^{36}$, which involves a randomly administered cross-sectional survey via door-to-door sampling. Surveys were completed by the main cook of the household and included questions on cooking fuel use from a WHO harmonized survey for monitoring Sustainable Development Goal 7 indicators ${ }^{37}$. The full questionnaire is available in the Supplementary Information. The final analytical sample included 5,638 households (Obuasi, Ghana, 1,987 (35\%); Mbalmayo, Cameroon, 1,811 (32\%) and Eldoret, Kenya, 1,840 (33\%)).

The proportion of individuals who primarily cooked with LPG varied substantially by community (Obuasi 38\% $(n=757)$, Mbalmayo 28\% $(n=468)$ and Eldoret 5\% $(n=35))$ (Fig. 1$)$. Of the households, $60 \%(n=2,772)$ 'stacked' at least two cooking fuels. Fuel stacking was $30 \%$ higher among households that primarily used LPG (82\%) compared with households that primarily used polluting fuels (53\%). Fuel-stacking prevalence among households that primarily cooked with polluting fuels was approximately $20 \%$ higher in Eldoret ( $60 \%)$ and Mbalmayo ( 60\%) compared with Obuasi ( 40\%) (Supplementary Table 2 ).

A higher percentage of households that primarily cooked with LPG contained a member with a university degree (22\%) and were in the highest income quartile (23\%), compared with households that primarily used polluting cooking fuels ( $5 \%$ with a university degree and $8 \%$ in the highest income quartile) (Supplementary Table 2). In Eldoret and Mbalmayo, the proportion of households cooking primarily with polluting fuels and reported seasonal changes in income (72 and $75 \%$, respectively) was $20-30 \%$ higher than those that primarily cooked with LPG (42 and 58\%, respectively). Among households that primarily cooked with LPG, 59\% had fewer than five family members, compared with $38 \%$ of those that primarily cooked with polluting fuels (Supplementary Table 2).

\section{Households that cook with LPG}

Over half $(55 \%, n=1,567)$ of the 2,830 households cooking with LPG used it as a primary fuel; very few $(4 \%, n=109)$ exclusively cooked with LPG and $44 \%(n=1,263)$ used LPG as a secondary fuel (Table 1). In Obuasi, two-thirds of households reported using LPG as a primary fuel $(67 \%, n=679)$ compared with one-third $(37 \%$, $n=316$ ) of households in Eldoret; in Mbalmayo, LPG was used roughly equally as a primary and secondary fuel $(48 \%, n=463)$. LPG was most frequently stacked with wood in Mbalmayo, and with charcoal in Eldoret and Obuasi (Fig. 2).

Nearly half (47\%) of households that primarily cooked with LPG said it was not always available for purchase (Table 1), more than double that for those exclusively cooking with LPG (21\%)). LPG consumption varied substantially from 0.8 to $67.0 \mathrm{~kg} \mathrm{capita}^{-1} \mathrm{yr}^{-1}$. Median LPG consumption was $14.4 \mathrm{~kg}_{\text {capita }}{ }^{-1} \mathrm{yr}^{-1}$ (interquartile range (IQR) $10.4,24.0$ ) in Eldoret, $20.0 \mathrm{~kg}_{\text {capita }}{ }^{-1} \mathrm{yr}^{-1}$ (IQR $15.0,30.0$ ) in Mbalmayo and $23.2 \mathrm{~kg} \mathrm{capita}^{-1} \mathrm{yr}^{-1}$ (IQR 14.5, 36.0) in Obuasi. The mean cost of cylinder refills was lowest among households exclusively cooking with LPG (US\$0.99 $\mathrm{kg}^{-1}$ (s.d. 0.50)) and highest among households using LPG as a secondary fuel (US\$1.27 kg-1 (s.d. 0.67)).

In Eldoret, $72 \%$ of the participants cooking exclusively with LPG were ten minutes or less from a retailer compared with 47 and $36 \%$ of households using LPG as a primary or secondary fuel, respectively. Electing to walk to an LPG retailer to obtain cylinder refills was six times more common among participants in Eldoret using LPG exclusively (61\%) than among those using LPG as a secondary fuel $(11 \%)$.

\section{Modelling of LPG as a primary or secondary fuel choice}

The final multivariable model modestly characterized (pseudo $R_{\text {marginal }}^{2}=0.42$, receiver operating characteristic $\left.=0.82\right)$ primary versus secondary use of LPG for cooking (Supplementary Table 4$)$. Demographics $\left(R_{\text {marginal }}^{2}=0.11\right)$ and LPG supply-related factors $\left(R_{\text {marginal }}^{2}=0.10\right)$ explained a higher proportion of model variability than SES $\left(R_{\text {marginal }}^{2}=0.03\right)$ (Supplementary Table 4$)$. Households with 1-2 members had more than twice the predicted probability $(84 \%(95 \%$ CI, 68,93$))$ of primarily using LPG than households with 7-8 family members (35\% (95\% CI, 17, 58)) (Table 2). Lower availability of LPG and higher refill costs were associated with a lower predicted probability of primary use of the fuel in a monotonically decreasing manner (Fig. 3). Specifically, $69 \%(95 \% \mathrm{CI}, 47,85)$ of households that report a refill cost of $<\mathrm{US} \$ 0.86 \mathrm{~kg}^{-1}$ were predicted to use LPG as a primary fuel, compared with $60 \%$ (95\% CI, 40, 80), 52\% (95\% CI, 30, 73) and $40 \%$ (95\% CI, 20, 64) of households that reported a cylinder refill cost of US\$0.86-1.00 kg- US\$1.01-1.10 kg-1 and $>$ US $\$ 1.10 \mathrm{~kg}^{-1}$, respectively. As the number of family members living in the household increased, a higher number of LPG stove burners was associated with a greater proportion of households that reported the use of LPG as a primary fuel; nearly $60 \%$ of households with a large family size ( $\geq 7$ members) using LPG as a primary cooking fuel owned a 3-4 burner stove, compared with less than $30 \%$ of smaller households (1-2 members) that primarily cooked with LPG (Supplementary Fig. 1).

\section{Modelling of annual per capita LPG consumption}

Half $\left(R_{\text {marginal }}^{2}=0.49\right.$; cross-validation $\left.R^{2}=0.39\right)$ of the variability in LPG consumption was explained by covariates included in the final model (root mean square error $=0.52 \mathrm{~kg} \mathrm{capita}^{-1} \mathrm{yr}^{-1}$; cross-validation root mean square error $\left.=0.54 \mathrm{~kg} \mathrm{capita}^{-1} \mathrm{yr}^{-1}\right)$ (Supplementary Table 5). Household demographics $\left(R_{\text {marginal }}^{2}=0.31\right)$ explained substantially more of this variability than household SES $\left(R_{\text {marginal }}^{2}=0.0\right)$. Households with 3-4 members consumed an average of $13.7 \mathrm{~kg} \mathrm{capita}^{-1} \mathrm{yr}^{-1}(95 \% \mathrm{CI},-17.2,-9.4)$, less than households with 1-2 individuals (Table 3 ). 


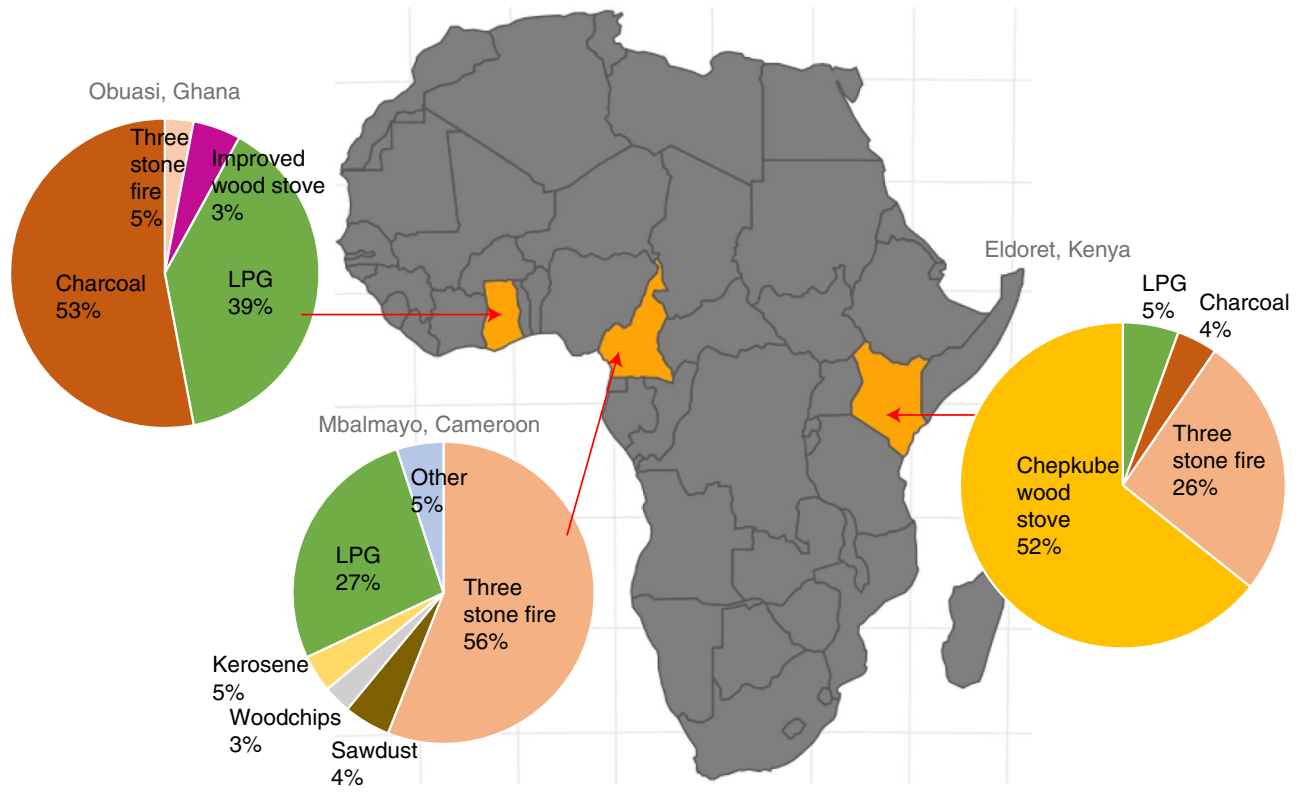

Fig. 1 | Primary cooking fuel types among three peri-urban communities in Ghana, Cameroon and Kenya. Cooking fuel percentages $(n=4,555)$ are presented among 757 households in Eldoret, rather than the full sample of 1,840 households because random sampling was switched to purposive sampling midway through the data collection. This was done to ensure a higher sample of LPG households available for subsequent phases of the CLEAN-Air(Africa) study in Eldoret.

Households that used a double-burner or triple-burner LPG stove consumed an average of 8.1 (95\% CI, 3.6, 13.8) or $6.7(95 \%$ CI, 2.4, 11.7) $\mathrm{kg}$ capita $^{-1} \mathrm{yr}^{-1}$, respectively, more LPG than households with single-burner stoves, irrespective of SES and family size (Table 3). Households that exclusively cooked with LPG consumed $2.5 \mathrm{~kg}_{\text {capita }}{ }^{-1} \mathrm{yr}^{-1}(95 \% \mathrm{CI}, 0.4,4.3)$ more than households that stacked LPG with another fuel (Table 3 ).

Participants that required 11-20 minutes, 21-30 minutes or $>30$ minutes to travel to LPG retailers consumed an average of 0.9 (95\% CI, -3.9, 2.9), 1.2 (95\% CI, -4.2, 2.7) and 1.3 (95\% CI, -4.2 , 2.4) $\mathrm{kg}$ capita $^{-1} \mathrm{yr}^{-1}$ less than those who could reach an LPG retailer in 10 minutes or less (Table 3). In addition, households that reported a lowest cost of LPG cylinder refills $\left(<\mathrm{US} \$ 0.86 \mathrm{~kg}^{-1}\right)$ consumed 3.2 (95\% CI, -6.4, 0.8), 3.9 (95\% CI, -7.2, 0.1) and 6.0 (95\% CI, -9.0,-2.2) $\mathrm{kg}_{\text {capita }} \mathrm{yr}^{-1}$ more than participants who reported higher refill costs of US $\$ 0.86-1.00 \mathrm{~kg}^{-1}$, US $\$ 1.01-1.10 \mathrm{~kg}^{-1}$ and $>\mathrm{US} \$ 1.10 \mathrm{~kg}^{-1}$, respectively. A similar monotonically decreasing relationship was found between a higher transportation cost to reach the LPG retailer and an average per capita LPG consumption (Fig. 4).

\section{Households that exclusively cook with polluting fuels}

Among households that exclusively cook with polluting fuels $(n=2,685)$, nearly half $(47 \%, n=1,248)$ reported they had previously cooked with LPG (Supplementary Table 6); the proportion varied nearly threefold by community (Obuasi 63\% $(n=612)$, Mbalmayo 48\% $(n=399)$ and Eldoret $24 \%(n=237))$. Only $10 \%$ $(n=272)$ of households that cooked exclusively with polluting fuels indicated being satisfied with their current cooking fuel.

Inability to afford the upfront costs of purchasing LPG stoves and/or equipment was the dominant reason $(70 \%, n=1,889)$ reported for not currently cooking with LPG (Fig. 5). High refill costs were cited as a barrier for LPG use by twice as many households that previously cooked with LPG (37\%) as those that had not (19\%) (Supplementary Table 6). LPG safety concerns were reported by $18 \%(n=470)$ of households not currently using LPG; this concern was highest in Obuasi $(30 \%, n=292)$; the proportion was twice as high as that in Mbalmayo $(14 \%, n=117)$ and five times higher than that in Eldoret $(6 \%, n=61)$.

\section{Discussion}

By quantitatively modelling the impact of demand and supply-side indicators on LPG usage, this multinational study demonstrates that both types of factors influence rates of LPG consumption in peri-urban communities in SSA. Although the prevalence of exclusive LPG users in the study sample was minimal (4\%), a $20 \%$ higher prevalence of a consistent availability of LPG reported among exclusive LPG users in Obuasi and Eldoret compared with that for households that stacked LPG with a polluting fuel (Supplementary Table 3) indicates that an unreliable supply of LPG is a critical deterrent to a full transition to clean cooking. Additionally, cooking with LPG exclusively rather than stacking with a polluting fuel was associated with a significantly (20\%) higher annual LPG consumption (average increase from 13.3 to $15.8 \mathrm{~kg} \mathrm{capita}^{-1} \mathrm{yr}^{-1}$ ) (Table 3). This importantly indicates that a higher per capita consumption among our study sample was not only due to households that cooked more on both LPG and traditional stoves (for example, due to a larger family size), but also that stacked fuels at a lower rate.

Households indicating that LPG was always available at retailers had a $25 \%$ higher predicted probability of using LPG as a primary fuel than those that reported that it was unavailable for purchase at least once per month, irrespective of household SES (Table 2). Households reporting the lowest LPG cylinder refill costs also had a $30 \%$ higher probability of primarily using LPG (Table 2) and consumed $6.0 \mathrm{~kg}_{\text {capita }}{ }^{-1} \mathrm{yr}^{-1}(95 \% \mathrm{CI}, 2.2,9.0)$ more than households that reported the highest refill costs (Table 3 ). Unaffordable LPG cylinder refill costs were commonly reported by households that cooked exclusively with polluting fuels, particularly in Obuasi (50\%) and Mbalmayo (40\%). This is possibly indicative of customers who use smaller cylinders $(6 \mathrm{~kg})$ in Eldoret being less sensitive to changes in the refill price compared with those using $>12 \mathrm{~kg}$ cylinders in Cameroon and Ghana. As an increasing LPG cylinder refill cost (per kilogram) was negatively associated with consumption in a monotonically decreasing manner (Fig. 4), and $37 \%$ of previous LPG users cited LPG cylinder refill costs as their main reason for the discontinued use of the fuel (Fig. 5), the cost of LPG cylinder refills emerged as a critical barrier among both current and former LPG users. 
Table 1 | LPG usage characteristics among households that reported exclusive, primary or secondary use of $L P G(n=2,830)$

\begin{tabular}{|c|c|c|c|}
\hline & Exclusive $(n=109)$ & Primary $(n=1,458)$ & Secondary $(n=1,263)$ \\
\hline \multicolumn{4}{|l|}{ Unavailability of fuel (times $\left.\mathrm{yr}^{-1}\right)$} \\
\hline Always available & $86(79 \%)$ & $779(53 \%)$ & $613(49 \%)$ \\
\hline$<4$ & $12(11 \%)$ & $396(27 \%)$ & $321(25 \%)$ \\
\hline $4-12$ & $8(7 \%)$ & $124(9 \%)$ & $170(13 \%)$ \\
\hline$>12$ & $3(3 \%)$ & $79(5 \%)$ & $102(8 \%)$ \\
\hline Don't know & 0 & $80(5 \%)$ & $57(5 \%)$ \\
\hline \multicolumn{4}{|l|}{ Usage (no. of days the previous week) } \\
\hline 0 & $5(5 \%)$ & $66(5 \%)$ & $274(22 \%)$ \\
\hline $1-3$ & $18(17 \%)$ & $105(7 \%)$ & $179(14 \%)$ \\
\hline $4-6$ & $8(7 \%)$ & $190(13 \%)$ & $148(12 \%)$ \\
\hline 7 & $78(72 \%)$ & $1,079(74 \%)$ & $629(50 \%)$ \\
\hline \multicolumn{4}{|l|}{ Years cooking with LPG } \\
\hline$<1$ & $12(11 \%)$ & $112(8 \%)$ & $158(13 \%)$ \\
\hline $1-2$ & $40(37 \%)$ & $437(30)$ & $348(28 \%)$ \\
\hline $2-5$ & $11(10 \%)$ & $57(4 \%)$ & $103(8 \%)$ \\
\hline $5-10$ & $21(19 \%)$ & $529(36 \%)$ & $333(26 \%)$ \\
\hline$>10$ & $25(23 \%)$ & $306(21 \%)$ & $288(23 \%)$ \\
\hline \multicolumn{4}{|l|}{ Cylinder size $(\mathrm{kg})$} \\
\hline 6 & $56(51 \%)$ & $457(31 \%)$ & $439(35 \%)$ \\
\hline 9 & $4(4 \%)$ & $18(1 \%)$ & $9(1 \%)$ \\
\hline 12.5 & $1(1 \%)$ & $464(31 \%)$ & $466(37 \%)$ \\
\hline 13 & $4(4 \%)$ & $79(6 \%)$ & $71(6 \%)$ \\
\hline 14.5 & $42(38 \%)$ & $292(20 \%)$ & $60(6 \%)$ \\
\hline Consumption (kg capita $\left.\mathrm{yr}^{-1}\right)$, median (IQR) & $29.0(7.2,18.8)$ & $20.0(13.6,29.0)$ & $12.0(7.2,18.8)$ \\
\hline Refill cost $\left(U S \$ \mathrm{~kg}^{-1}\right)$, mean (s.d.) & $0.99(0.50)$ & $1.05(0.59)$ & $1.27(0.67)$ \\
\hline \multicolumn{4}{|l|}{ Travel time to refill point (min) } \\
\hline Home delivery & $11(10 \%)$ & $103(7 \%)$ & $48(4 \%)$ \\
\hline $1-10$ & $38(35 \%)$ & $390(27 \%)$ & $349(28 \%)$ \\
\hline $11-20$ & $20(18 \%)$ & $437(30 \%)$ & $398(32 \%)$ \\
\hline $21-30$ & $23(21 \%)$ & $349(24 \%)$ & $363(29 \%)$ \\
\hline $30+$ & $17(16 \%)$ & $162(11 \%)$ & $72(6 \%)$ \\
\hline \multicolumn{4}{|l|}{ Transportation mode for refill } \\
\hline Motorbike & $12(11 \%)$ & $593(41 \%)$ & $804(64 \%)$ \\
\hline Car & $32(29 \%)$ & $363(25 \%)$ & $167(13 \%)$ \\
\hline On foot & $32(29 \%)$ & $210(14 \%)$ & $122(10 \%)$ \\
\hline Public transport & $22(20 \%)$ & $172(12 \%)$ & $85(7 \%)$ \\
\hline Home delivery & $11(10 \%)$ & $103(7 \%)$ & $48(4 \%)$ \\
\hline \multicolumn{4}{|l|}{ Number of cylinders owned } \\
\hline 1 & $77(71 \%)$ & $976(67 \%)$ & $1,001(79 \%)$ \\
\hline 2 & $25(23 \%)$ & $353(24 \%)$ & $189(15 \%)$ \\
\hline $3+$ & $7(6 \%)$ & $111(8 \%)$ & $40(3 \%)$ \\
\hline \multicolumn{4}{|l|}{ Number of stove burners } \\
\hline 1 & $58(53 \%)$ & $460(32 \%)$ & $536(42 \%)$ \\
\hline 2 & $10(9 \%)$ & $339(23 \%)$ & $308(24 \%)$ \\
\hline $3+$ & $41(38 \%)$ & $641(44 \%)$ & $385(30 \%)$ \\
\hline \multicolumn{4}{|l|}{ Time since last stove purchase (yr) } \\
\hline$<2$ & $43(54 \%)$ & $645(56 \%)$ & $502(47 \%)$ \\
\hline $3-4$ & $17(22 \%)$ & $244(21 \%)$ & $236(22 \%)$ \\
\hline $5-6$ & $10(13 \%)$ & $134(12 \%)$ & $163(15 \%)$ \\
\hline $7+$ & $9(11 \%)$ & $130(11 \%)$ & $167(16 \%)$ \\
\hline
\end{tabular}

${ }^{a}$ Annual per capita LPG consumption is a derived variable. The number of annual refills was obtained by dividing one year by the average duration that the LPG cylinder typically lasts before it runs empty. The number of refills was then multiplied by cylinder size ( $\mathrm{kg}$ ) and divided by the number of household members (reported in Supplementary Table 2). 

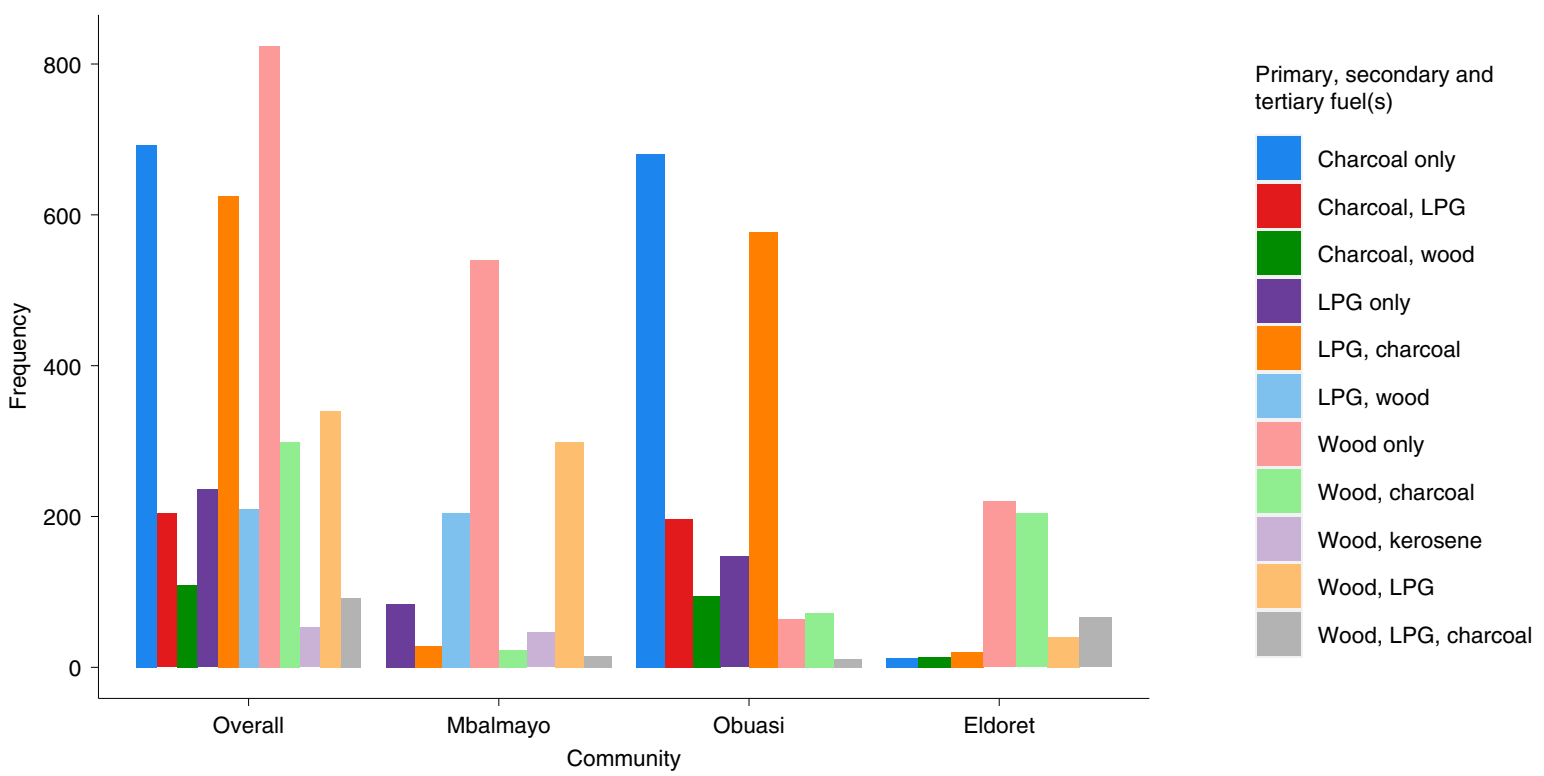

Fig. 2 | Most common primary, secondary and tertiary cooking fuel combinations by community. For brevity, only the most common fuel combinations (>35 households) were included. Among the study households, there were nearly 200 different cooking fuel combinations.

Moreover, using a double-burner LPG stove was associated with a $8.1 \mathrm{~kg}$ capita $^{-1} \mathrm{yr}^{-1}(95 \% \mathrm{CI}, 3.6,13.8)$ higher LPG consumption compared with use of a single-burner stove (Table 3). Further, using a multiburner LPG stove was linked to a greater probability of households that primarily used LPG, particularly those with five members or more (Supplementary Fig. 2). These findings probably reflect the greater time and fuel savings multiburner stoves offer to larger families due to the ability to use multiple pots or pans simultaneously ${ }^{38}$. The ability to cook two meals simultaneously on double-burner stoves was an advantage of LPG over kerosene reported by households in Nairobi ${ }^{39}$, and participants in another Kenyan study stated they had 'no need to stack' when using double-burner stoves ${ }^{40}$. This study adds to the growing body of evidence that, once the barrier of initial LPG access is overcome, families value the practicalities of cooking (for example. time and fuel savings), which can be influenced by supply-related factors aside from fuel price alone. Governments should promote multiburner stoves (as in India with the PMUY programme) ${ }^{26}$ as a potentially highly effective intervention to scale-up the more exclusive use of clean cooking.

Higher transportation cost and longer time to obtain an LPG refill were associated with lower LPG consumption in a monotonically decreasing manner (Table 3). This finding matches that of previous cooking fuel choice research conducted in rural communities in Ghana $^{41-43}$. Policies that improve the proliferation of last-mile LPG distributors and retailers are probably needed in these peri-urban communities to decrease the travel time and costs associated with acquiring cylinder refills. Other LPG supply-chain enhancements, such as increased cylinder inventory, bulk storage and filling facilities, may ultimately lead to a greater population-level consumption of $\mathrm{LPG}^{29}$. These supply-related policies were identified as a priority by the governments of all three countries ${ }^{17,44,45}$.

Additionally, consumer finance mechanisms, which includes unconditional cash transfers ${ }^{46}$, microfinance ${ }^{47}$ and pay-as-you-go LPG were shown to increase or sustain the use of LPG. Pay-as-you-go LPG, which removes transportation times and costs via the direct home delivery of LPG cylinders, has been successfully rolled out in urban settings, but will be more logistically challenging to implement in peri-urban areas due to the higher transportation costs and enhanced distribution networks needed to ensure timely home deliveries ${ }^{17}$.

In India, the PMUY programme rapidly expanded LPG access among the poorest, but did not lead to a higher usage among rural households $\mathrm{s}^{25,48}$. A study among 8,000 PMUY programme beneficiaries similarly proposed that long travel times from rural Indian villages to refill points was a likely driver of a $30 \%$ lower LPG consumption ${ }^{26}$. Although the Indian study proposed that LPG access is important at a village level, we found that accessibility may play a role at smaller scales in an African context; a 10-minute-longer travel time to a retailer within a community was a deterrent to LPG usage (Fig. 4). These results contribute to growing evidence that accessibility, in addition to affordability, of LPG refills should be targeted by policymakers to expand LPG use.

Younger households and smaller families were more likely to primarily use LPG and had higher consumption rates (Fig. 5), which is similar to findings from a study of PMUY beneficiaries in India ${ }^{26}$. As household size increases, there is generally a demand for a greater amount of fuel and stove surface area to prepare larger meals to feed the entire family. Thus, open fires that accommodate larger pots can be more practical for substantive cooking than a single-burner LPG stove $^{38,49}$. Moreover, it is typically easier for families with more children to collect biomass as there are more hands available to attend to other household chores ${ }^{50}$; one-fifth $(21 \%)$ of households with 7 or more family members in our sample obtained free fuelwood for cooking compared with only $8 \%$ of households with 1-2 inhabitants (Supplementary Table 10).

In contrast to a study in India ${ }^{25}$, years spent cooking with LPG was not significantly associated with consumption, which potentially highlights the importance of LPG fuel costs remaining price competitive in the long term to prevent reversion to polluting cooking fuels. This finding is further supported by households previously cooking with LPG being more likely than households with no prior LPG experience to cite high cylinder refill costs as a reason for not cooking with LPG (Supplementary Table 6). Household income was not significantly associated with use of LPG as a primary fuel (Table 2), which demonstrates that usage does not necessarily intensify in a linear manner with increasing SES, but may follow a complicated trajectory due to various supply-related and contextual factors ${ }^{51,52}$. 
Table 2 | Coefficients from LPG primary versus secondary cooking fuel logistic regression model

\begin{tabular}{|c|c|c|c|c|c|}
\hline Coefficient & Estimate & Standard error & $\begin{array}{l}\text { Test statistic } \\
\text { (Z-score) }\end{array}$ & $P$ value & $\begin{array}{l}\text { Predicted probability } \\
(95 \% \mathrm{Cl})\end{array}$ \\
\hline Intercept & 1.30 & 0.55 & 2.36 & $0.03^{\star}$ & \\
\hline Country (referenced to Ghana) & & & & & $0.69(0.47,0.85)$ \\
\hline Cameroon & -0.73 & 0.57 & -1.26 & 0.21 & $0.55(0.32,0.77)$ \\
\hline Kenya & -0.79 & 0.66 & -1.19 & 0.23 & $0.47(0.24,0.72)$ \\
\hline Household income quartile (referenced to 1st quartile (lowest)) & & & & & $0.69(0.47,0.85)$ \\
\hline 2nd quartile & 0.12 & 0.17 & 0.70 & 0.48 & $0.71(0.50,0.86)$ \\
\hline 3rd quartile & -0.01 & 0.20 & -0.06 & 0.95 & $0.67(0.46,0.83)$ \\
\hline 4th quartile (highest) & 0.15 & 0.25 & 0.59 & 0.56 & $0.70(0.49,0.86)$ \\
\hline Highest level of education in household & & & & & $0.69(0.47,0.85)$ \\
\hline Primary & 0.20 & 0.34 & 0.59 & 0.55 & $0.79(0.61,0.90)$ \\
\hline Junior high & 0.65 & 0.42 & 1.56 & 0.12 & $0.70(0.51,0.84)$ \\
\hline Secondary & 0.80 & 0.32 & 2.48 & $0.01^{\star}$ & $0.81(0.66,0.90)$ \\
\hline College or university & 1.22 & 0.34 & 3.60 & $<0.001^{\star \star \star}$ & $0.87(0.74,0.94)$ \\
\hline Age (yr) of head of household (referenced to 18-24) & & & & & $0.69(0.47,0.85)$ \\
\hline $25-29$ & -0.09 & 0.16 & -0.54 & 0.59 & $0.67(0.46,0.83)$ \\
\hline $30-35$ & -0.22 & 0.16 & -1.27 & 0.20 & $0.65(0.43,0.82)$ \\
\hline $36-75$ & -0.37 & 0.15 & -2.33 & $0.02^{\star}$ & $0.61(0.39,0.79)$ \\
\hline Sex of cooking fuel decision maker (referenced to female) & & & & & $0.69(0.47,0.85)$ \\
\hline Male & 0.55 & 0.15 & 3.61 & $<0.001^{\star \star \star}$ & $0.79(0.59,0.90)$ \\
\hline Number of household members (referenced to 1-2) & & & & & $0.84(0.68,0.93)$ \\
\hline $3-4$ & -0.87 & 0.21 & -3.99 & $<0.001^{\star \star \star}$ & $0.69(0.47,0.85)$ \\
\hline $5-6$ & -1.57 & 0.22 & -7.06 & $<0.001^{\star \star \star}$ & $0.52(0.31,0.73)$ \\
\hline $7+$ & -2.31 & 0.24 & -9.52 & $<0.001^{\star \star \star}$ & $0.35(0.17,0.58)$ \\
\hline $\begin{array}{l}\text { Number of children under } 5 \text { years old living in household } \\
\text { (referenced to 1) }\end{array}$ & & & & & $0.69(0.47,0.85)$ \\
\hline 2 & 0.23 & 0.13 & 1.68 & 0.09 & $0.74(0.53,0.87)$ \\
\hline $3-6$ & -0.19 & 0.16 & -1.14 & 0.25 & $0.65(0.42,0.83)$ \\
\hline Days cooking with LPG in previous week (referenced to 6 or less) & & & & & $0.69(0.47,0.85)$ \\
\hline 7 days (every day) & 1.15 & 0.12 & 9.18 & $<0.001^{\star \star \star}$ & $0.87(0.73,0.95)$ \\
\hline Obtain any cooking fuels for free & & & & & $0.69(0.47,0.85)$ \\
\hline Yes & -1.31 & 0.17 & -7.93 & $<0.001^{\star \star \star}$ & $0.37(0.18,0.60)$ \\
\hline $\begin{array}{l}\text { Transportation cost for obtaining LPG refill (referenced to } \\
<\text { US\$0.25) }\end{array}$ & & & & & $0.69(0.47,0.85)$ \\
\hline US $\$ 0.26-0.50$ & -0.40 & 0.18 & -2.24 & $0.02^{*}$ & $0.62(0.40,0.80)$ \\
\hline$\$ 0.51-1.00$ & -0.46 & 0.15 & -2.96 & $0.003^{\star \star}$ & $0.59(0.36,0.79)$ \\
\hline$>$ US\$1.00 & -0.27 & 0.15 & -1.72 & 0.08 & $0.63(0.39,0.81)$ \\
\hline Travel time to obtain LPG refill (referenced to $<10 \mathrm{~min}$ ) & & & & & $0.69(0.47,0.85)$ \\
\hline $11-20 \min$ & 0.03 & 0.14 & 0.20 & 0.84 & $0.70(0.48,0.85)$ \\
\hline $21-30 \mathrm{~min}$ & -0.35 & 0.15 & -2.26 & $0.02^{\star}$ & $0.61(0.39,0.80)$ \\
\hline$>30 \min$ & 0.44 & 0.25 & 1.72 & 0.09 & $0.75(0.54,0.89)$ \\
\hline LPG unavailable (referenced to often (more than once a month)) & & & & & $0.69(0.47,0.85)$ \\
\hline Sometimes (4-12 times a year) & 0.03 & 0.28 & 0.11 & 0.91 & $0.68(0.47,0.84)$ \\
\hline Rarely (less than 4 times a year) & 0.45 & 0.25 & 1.76 & 0.08 & $0.75(0.56,0.88)$ \\
\hline Never (always available) & 0.84 & 0.24 & 3.75 & $<0.001^{\star \star \star}$ & $0.84(0.69,0.92)$ \\
\hline Do not know/unsure & 0.42 & 0.33 & 1.25 & 0.21 & $0.75(0.54,0.89)$ \\
\hline Cost of refills $\left(U S \$ \mathrm{~kg}^{-1}\right)$ (referenced to $\left.<U S \$ 0.86 \mathrm{~kg}^{-1}\right)$ & & & & & $0.69(0.47,0.85)$ \\
\hline US\$0.86-1.00 kg-1 & -0.35 & 0.25 & -1.40 & 0.20 & $0.60(0.40,0.80)$ \\
\hline US\$1.01-1.10 kg-1 & -0.74 & 0.28 & -2.61 & $0.009^{\star \star}$ & $0.52(0.30,0.73)$ \\
\hline$>U S \$ 1.10 \mathrm{~kg}^{-1}$ & -1.30 & 0.33 & -3.88 & $<0.001^{\star \star \star}$ & $0.40(0.20,0.64)$ \\
\hline
\end{tabular}



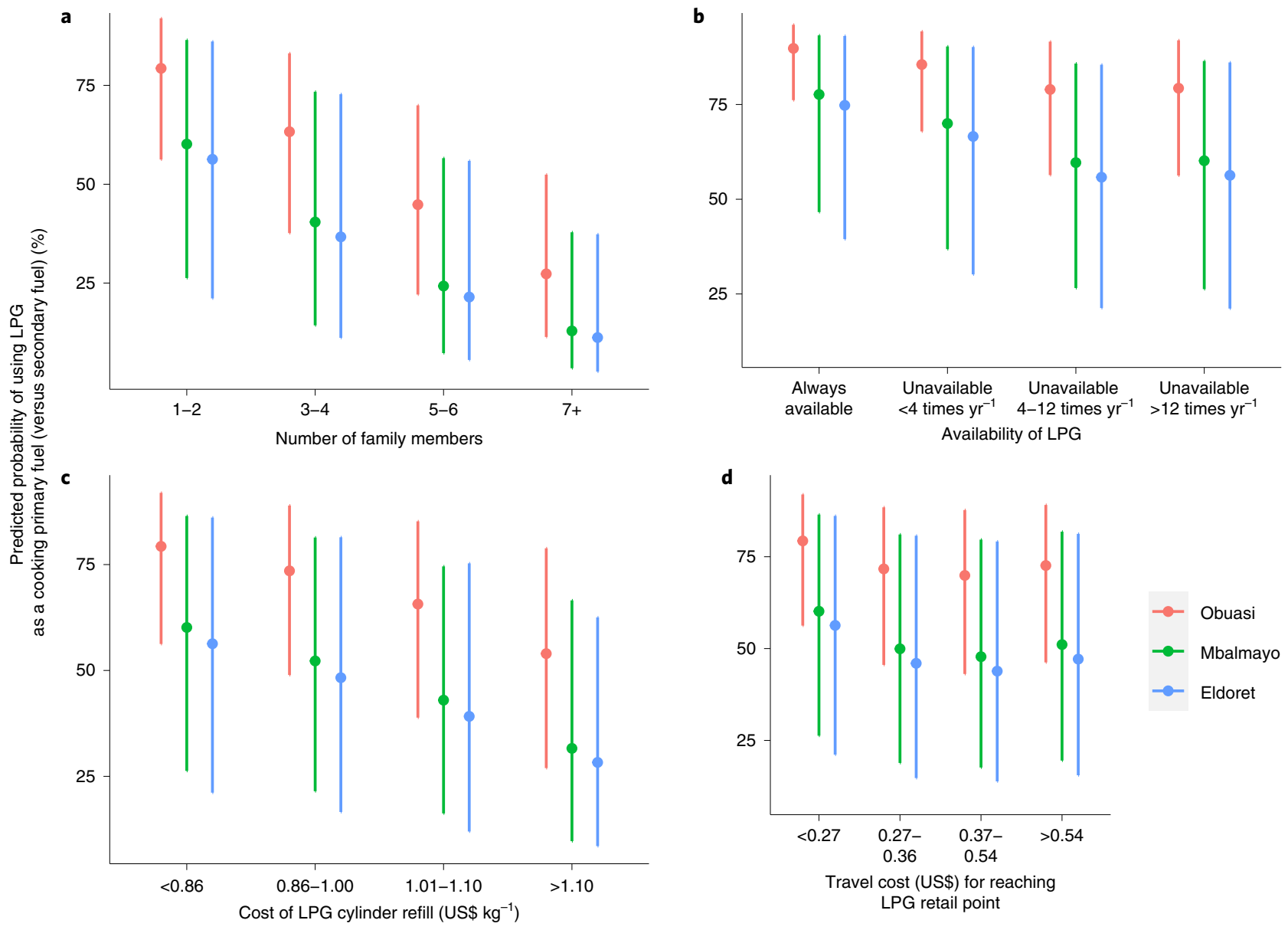

Fig. 3 | Average-adjusted predicted probabilities of using LPG as a primary versus secondary cooking fuel. Mean predicted probability of using LPG as a primary fuel along with error bars that represent $95 \%$ confidence intervals (Cls). Primary LPG households were those that indicated LPG as their main cooking fuel, whereas secondary LPG users were those that stated LPG was another fuel they used aside from their main cooking fuel. All probabilities account for quantitative covariates centred at their mean.

The estimated median annual LPG per capita consumptions in Mbalmayo, Eldoret and Obuasi were relatively similar (40\% higher, $13 \%$ higher and $8 \%$ lower, respectively) to national rates as last estimated in National Feasibility Assessments conducted by the Global LPG Partnership in 2017/2018 (14.2 $\mathrm{kgcapita}^{-1} \mathrm{yr}^{-1}$ in Cameroon, $12.8 \mathrm{kgcapita}^{-1} \mathrm{yr}^{-1}$ in Kenya and $25.0 \mathrm{kgcapita}^{-1} \mathrm{yr}^{-1}$ in Ghana) $)^{44,45,53}$. It is unclear if the differences result from geographical variation within countries, population-level changes in consumption from 2017 to 2019 or bias in the self-reporting of consumption (Supplementary Table 7), which has occurred in previous studies $^{54}$. Nonetheless, the self-reported consumption rates are about half those of households in more developed countries (for example, Brazil, Indonesia and Peru) with well-established LPG supply chains $^{18}$. The communities of Mbalmayo (27\%) and Obuasi (39\%) had a substantially higher prevalence of households that primarily cooked with LPG than those of Eldoret (5\%); the prevalence of households using LPG in Eldoret is consistent with the proportion of rural households using LPG in Kenya (6\%) reported in the 2019 Kenya Census ${ }^{55}$.

A lower prevalence and per capita LPG consumption in Eldoret compared with those in Obuasi and Mbalmayo are partially due to differences in national LPG policies between the three countries. In Cameroon, regulations regarding the storage and distribution of LPG have been in place since the $1970 \mathrm{~s}^{53}$. Despite instances of cylinder shortages over the past couple of decades, new foreign-owned companies entered the Cameroonian market in the mid-2000s, which increased the number of cylinders in circulation and raised population-level LPG consumption. The Ghana LPG promotion programme started in 1990 to encourage households to adopt $\mathrm{LPG}^{44}$. The Ghanaian government has subsidized LPG over the past several decades (although subsidies were phased out in 2013) and Ghana partially produced LPG from a local refinery and offshore natural gas extraction, which spurred a higher population use of LPG (including as a transport fuel). Ghana was the first country in SSA to endorse a Sustainable Energy for All Action Plan in 2012 under the United Nations. In Kenya, a lack of proper enforcement rules has led to the diffusion of illegal refilling practices, which makes it difficult for legitimate companies to operate sustainably. A lack of LPG pricing regulation in Kenya contributed to a higher price (per kilogram) of LPG in Eldoret than those in Obuasi and Mbalmayo (Supplementary Table 3).

LPG safety concerns were prevalent among households that cooked with polluting fuels, particularly in Obuasi (30\%) (Fig. 5). A higher proportion in Obuasi compared with those in the other communities is probably attributable to the 'customer-owned' cylinder model currently implemented in Ghana, which places customers in charge of cylinder maintenance and replacement, and thus contributes to more frequent serious LPG accidents $\mathrm{s}^{45}$. The Ghanaian government is transitioning the population to the "branded cylinder recirculation model, which ensures proper refilling practices and the correct disposal of cylinders, as LPG marketers are responsible for cylinder maintenance and safety ${ }^{56}$. 
Table 3 | Coefficients from log-linear regression and exponentiated consumption ( $k g$ capita ${ }^{-1} \mathrm{yr}^{-1}$ from LPG consumption model

\begin{tabular}{|c|c|c|c|c|c|}
\hline Coefficient & Estimate & Standard error & $\begin{array}{l}\text { Test statistic } \\
\text { (Wald statistic) }\end{array}$ & $P$ value & $\begin{array}{l}\text { Mean }(95 \% \mathrm{Cl}) \\
\left(\mathrm{kg} \mathrm{capita}^{-1} \mathrm{yr}^{-1}\right)\end{array}$ \\
\hline Intercept & 3.76 & 0.09 & 41.32 & $<0.001^{\star \star \star}$ & \\
\hline Country (referenced to Ghana) & & & & & $15.80(12.69,19.32)$ \\
\hline Cameroon & 0.04 & 0.05 & 0.86 & 0.39 & $14.70(11.71,18.05)$ \\
\hline Kenya & -0.02 & 0.07 & -0.27 & 0.78 & $13.24(10.80,15.83)$ \\
\hline Age of head of household (referenced to 18-24) & & & & & $16.43(13.24,20.40)$ \\
\hline $25-29$ & -0.04 & 0.03 & -1.20 & 0.23 & $15.82(12.80,19.55)$ \\
\hline $30-35$ & -0.01 & 0.03 & -0.58 & 0.56 & $16.29(13.12,20.22)$ \\
\hline $36-75$ & -0.05 & 0.03 & -1.38 & 0.17 & $15.63(12.59,19.39)$ \\
\hline $\begin{array}{l}\text { Household income quartile (referenced to 1st } \\
\text { quartile (lowest)) }\end{array}$ & & & & & $15.31(12.41,18.89)$ \\
\hline 2nd quartile & 0.05 & 0.04 & 1.36 & 0.17 & $15.65(12.69,19.31)$ \\
\hline 3rd quartile & 0.06 & 0.04 & 1.51 & 0.13 & $15.52(12.61,19.09)$ \\
\hline 4th quartile (highest) & 0.15 & 0.05 & 3.20 & $0.001^{\star \star}$ & $17.10(13.93,21.00)$ \\
\hline $\begin{array}{l}\text { Sex of cooking fuel decision maker (referenced } \\
\text { to female) }\end{array}$ & & & & & $15.31(12.41,18.89)$ \\
\hline Male & 0.01 & 0.03 & 0.34 & 0.73 & $15.55(12.56,19.25)$ \\
\hline Marital status (referenced to married) & & & & & $15.31(12.41,18.89)$ \\
\hline Divorced/separated & -0.11 & 0.07 & -1.50 & 0.12 & $12.57(9.71,16.26)$ \\
\hline Living together with partner/cohabiting & -0.08 & 0.04 & -1.87 & 0.06 & $14.76(11.86,18.37)$ \\
\hline Single & 0.01 & 0.02 & 0.39 & 0.70 & $16.10(13.12,19.76)$ \\
\hline Widowed & -0.03 & 0.05 & -0.52 & 0.58 & $15.54(12.24,19.73)$ \\
\hline $\begin{array}{l}\text { Number of household members (referenced to } \\
1-2 \text { ) }\end{array}$ & & & & & $32.05(26.04,39.46)$ \\
\hline $3-4$ & -0.60 & 0.04 & -15.7 & $<0.001^{\star \star \star}$ & $18.33(14.84,22.64)$ \\
\hline $5-6$ & -0.99 & 0.04 & -24.3 & $<0.001^{\star \star \star}$ & $12.40(10.02,15.34)$ \\
\hline $7+$ & -1.29 & 0.05 & -28.4 & $<0.001^{\star \star \star}$ & $9.11(7.33,11.32)$ \\
\hline $\begin{array}{l}\text { Number of children }<5 \text { years old living in } \\
\text { household (referenced to } 1 \text { ) }\end{array}$ & & & & & $17.20(13.93,21.23)$ \\
\hline 2 & -0.05 & 0.03 & -1.98 & $0.04^{*}$ & $14.53(11.74,17.98)$ \\
\hline $3-6$ & -0.14 & 0.03 & -4.04 & $<0.001^{\star \star \star}$ & $14.30(11.54,17.73)$ \\
\hline Years cooking with LPG (referenced to $<1 \mathrm{yr}$ ) & & & & & $15.31(12.41,18.89)$ \\
\hline $1-2 \mathrm{yr}$ & -0.09 & 0.06 & -1.64 & 0.10 & $13.96(11.44,17.02)$ \\
\hline $2-5 y r$ & -0.08 & 0.05 & -1.55 & 0.12 & $14.36(11.88,17.36)$ \\
\hline $5-10 \mathrm{yr}$ & -0.01 & 0.05 & -0.28 & 0.77 & $15.28(12.66,18.43)$ \\
\hline$>10 \mathrm{yr}$ & 0.00 & 0.05 & 0.03 & 0.97 & $16.06(13.22,19.49)$ \\
\hline Fuel stacking (referenced to no) & & & & & $15.80(12.81,19.49)$ \\
\hline Yes & -0.12 & 0.06 & -2.15 & $0.03^{*}$ & $13.29(11.44,15.43)$ \\
\hline $\begin{array}{l}\text { Days cooking with LPG in previous week } \\
\text { (referenced to } 6 \text { or less) }\end{array}$ & & & & & $15.31(12.41,18.89)$ \\
\hline 7 days (everyday) & 0.07 & 0.02 & 2.95 & $0.003^{\star \star}$ & $16.16(13.07,19.97)$ \\
\hline Obtain any cooking fuels for free & & & & & $15.80(12.81,19.49)$ \\
\hline Yes & -0.05 & 0.03 & -1.55 & 0.12 & $15.30(12.29,19.03)$ \\
\hline Number of LPG stove burners (referenced to 1) & & & & & $15.31(12.41,18.89)$ \\
\hline 2 & 0.40 & 0.03 & 11.13 & $<0.001^{\star \star \star}$ & $23.44(18.91,29.06)$ \\
\hline $3+$ & 0.31 & 0.03 & 9.21 & $<0.001^{\star \star \star}$ & $21.87(17.72,27.00)$ \\
\hline $\begin{array}{l}\text { Transportation cost for obtaining LPG refill } \\
(<\cup S \$ 0.25)\end{array}$ & & & & & $16.08(13.58,19.03)$ \\
\hline US $\$ 0.26-0.50$ & -0.01 & 0.03 & -0.38 & 0.70 & $16.06(13.52,19.08)$ \\
\hline US\$0.51-1.00 & -0.02 & 0.03 & -0.63 & 0.53 & $15.77(13.23,18.79)$ \\
\hline
\end{tabular}


Table 3 | Coefficients from log-linear regression and exponentiated consumption ( $\mathrm{kg} \mathrm{capita}^{-1} \mathrm{yr}^{-1}$ from LPG consumption model (continued)

\begin{tabular}{|c|c|c|c|c|c|}
\hline Coefficient & Estimate & Standard error & $\begin{array}{l}\text { Test statistic } \\
\text { (Wald statistic) }\end{array}$ & $P$ value & $\begin{array}{l}\text { Mean }(95 \% \mathrm{Cl}) \\
\left(\text { kg capita }^{-1} \mathrm{yr}^{-1}\right)\end{array}$ \\
\hline$>$ US\$1.00 & 0.00 & 0.03 & 0.17 & 0.86 & $16.02(13.42,19.12)$ \\
\hline $\begin{array}{l}\text { Travel time to obtain LPG refill (referenced } \\
\text { to }<10 \mathrm{~min} \text { ) }\end{array}$ & & & & & $16.56(13.36,20.53)$ \\
\hline $11-20 \mathrm{~min}$ & -0.06 & 0.03 & -2.05 & $0.04^{\star}$ & $15.73(12.71,19.46)$ \\
\hline $21-30 \mathrm{~min}$ & -0.09 & 0.03 & -2.95 & $0.003^{\star \star}$ & $15.41(12.28,19.33)$ \\
\hline Cost of refills (referenced to $<$ US $\$ 0.85 \mathrm{~kg}^{-1}$ ) & & & & & $19.69(15.81,24.51)$ \\
\hline U\$0.86-1.00 kg-1 & -0.09 & 0.04 & -2.22 & $0.03^{\star}$ & $16.50(13.25,20.53)$ \\
\hline US $\$ 1.01-1.10 \mathrm{~kg}^{-1}$ & -0.16 & 0.05 & -3.03 & $0.003^{\star \star}$ & $15.75(12.54,19.79)$ \\
\hline$>$ US $\$ 1.10 \mathrm{~kg}^{-1}$ & -0.36 & 0.06 & -5.50 & $<0.001^{\star \star \star}$ & $13.68(10.71,17.47)$ \\
\hline
\end{tabular}

$n=2,330$. All the covariates were mean centred. $P$ values were generated from two-sided $t$-tests. No adjustments were made for multiple comparisons. ${ }^{\star} P<0.05,{ }^{\star \star} P<0.01,{ }^{\star \star \star} P<0.001$.
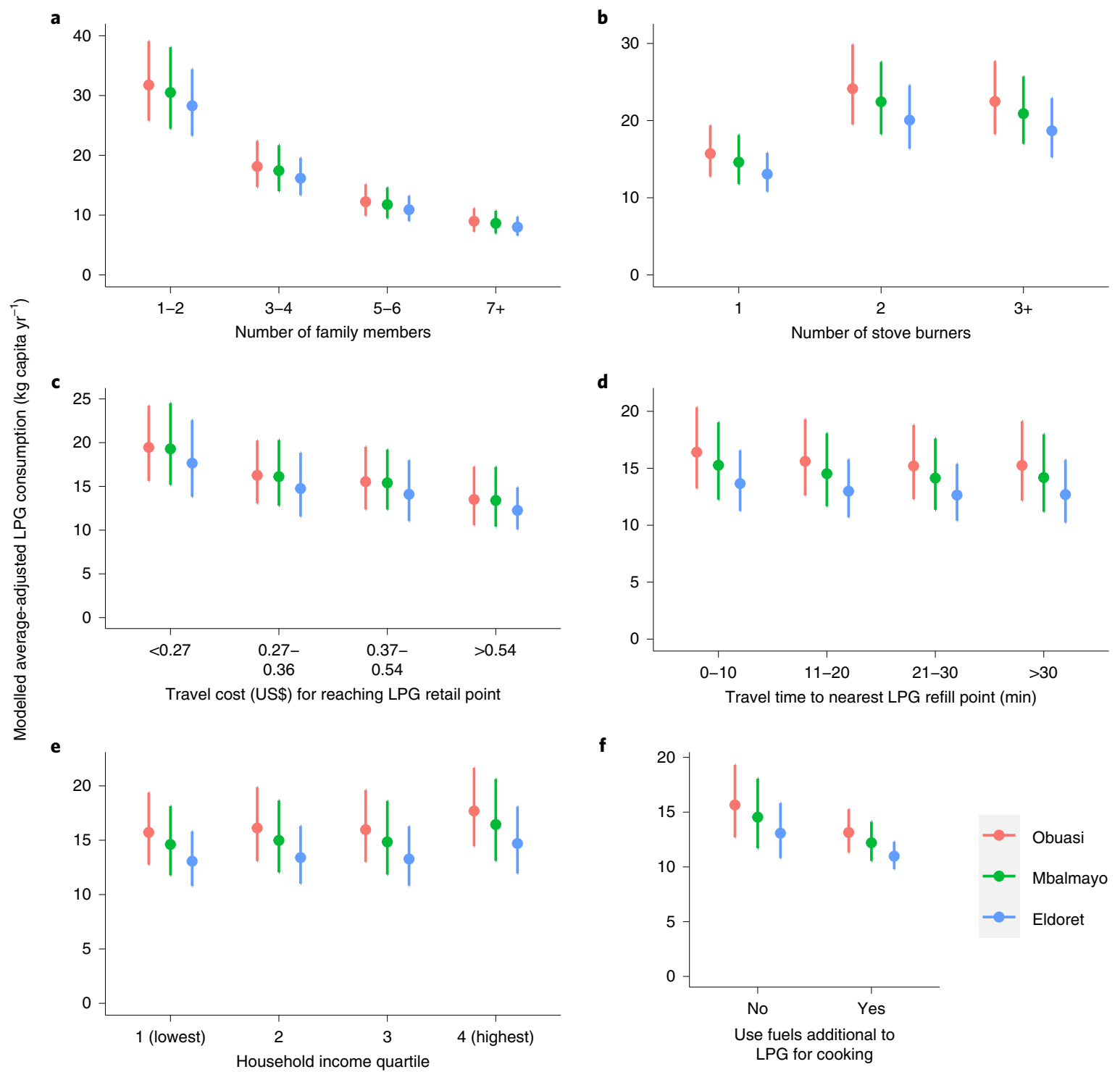

$\mathbf{f}$

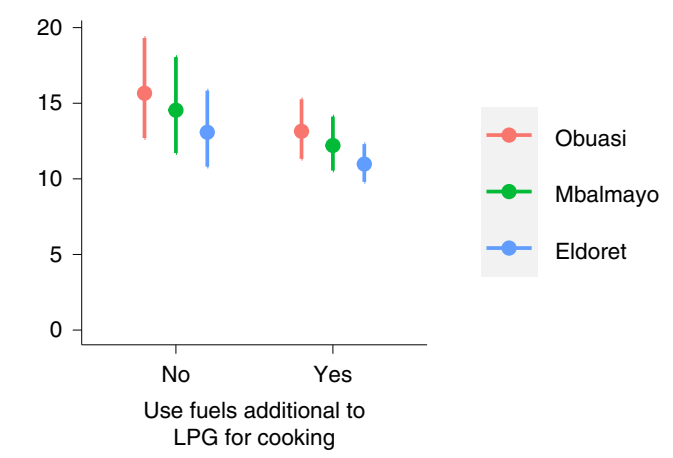

Fig. 4 | Average-adjusted annual per capita LPG consumption. Mean LPG consumption along with error bars that represent 95\% Cls. Annual per capita consumption was obtained by dividing 12 months by the self-reported average duration (months) until a typical cylinder refill runs empty, multiplying that quantity by the LPG cylinder size and dividing by the number of household members. Per capita consumption is presented with covariates centred at their mean. 


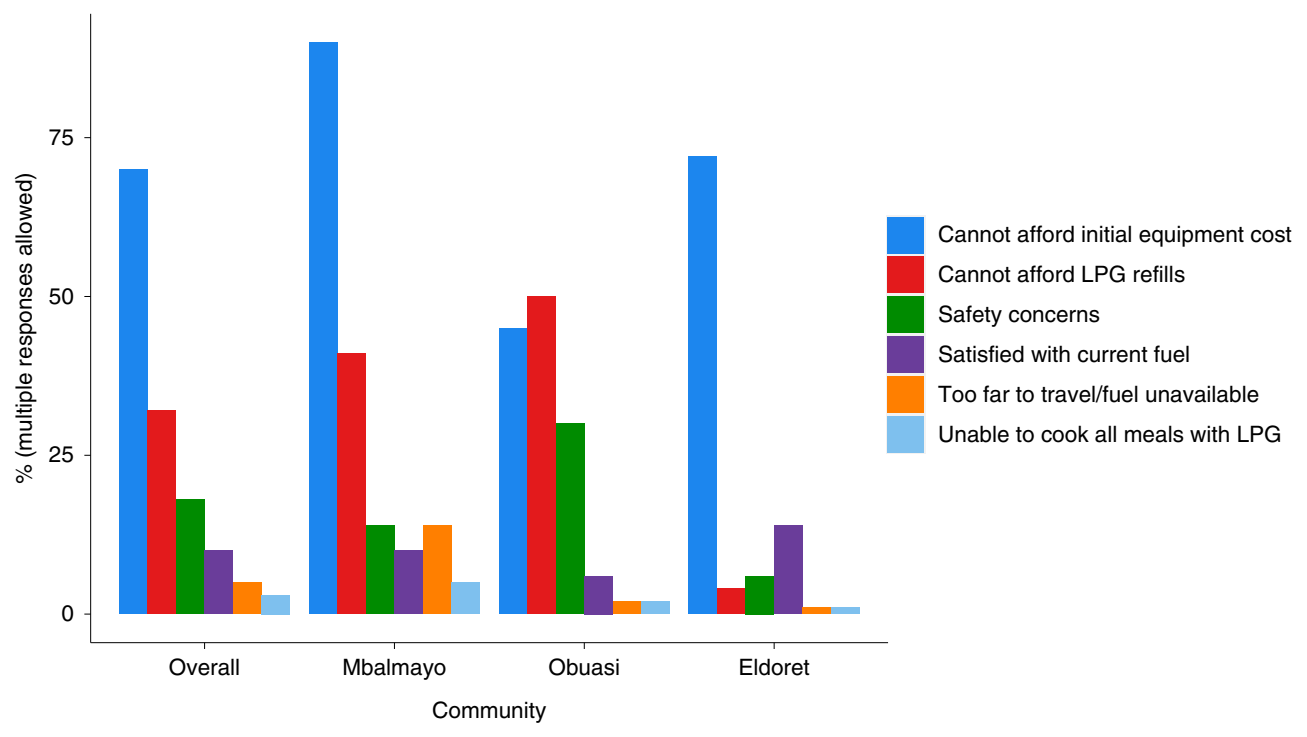

Fig. 5 | Reasons for not cooking with LPG among households exclusively cooking with polluting fuels. $n=2,685$.

Participants in Eldoret who gathered firewood at no cost $(42 \%$ of households compared with $5 \%$ in Obuasi and 22\% in Mbalmayo (Supplementary Table 9)) were substantially less likely to purchase LPG for cooking (Supplementary Table 2). Further, households that purchased all their cooking fuels had nearly twice the probability (69\%) of using LPG as the primary cooking fuel compared with households that gathered free fuelwood (37\%) (Table 2). The ability to collect free firewood, assessed via forest cover as a proxy in some studies $^{57}$, is a well-documented deterrent to LPG consumption ${ }^{16}$ and can lead to the discontinuation of LPG use among households in $\mathrm{SSA}^{58}$

The reversion from clean to polluting cooking fuels is reported in longitudinal studies ${ }^{35}$, with a prevalence as high as $35 \%$ (China) $)^{59}$. Likewise, this study uncovered that $47 \%$ of households that exclusively cooked with polluting fuels had formerly cooked with LPG (Supplementary Table 6). Although unable to ascertain whether these households previously used LPG as their primary fuel, and whether participants have completely stopped using it or routinely switch between fuels (for example, due to periodic income fluctuations), unaffordable LPG refill costs played a key role in $37 \%$ of household decisions to discontinue their use of LPG (Supplementary Table 6). Nonetheless, there was high aspiration to cook with clean fuels among households that reverted to cooking with biomass, with only $7 \%$ reporting satisfaction with their current polluting fuel.

\section{Strengths and limitations}

This study was statistically powered to examine supply- and demand-related determinants of LPG consumption in SSA. Although the calculation of self-reported annual LPG consumption via two different survey questions showed disagreement (Supplementary Fig. 3), sensitivity analyses revealed that this discrepancy did not substantially impact the modelling results (Supplementary Table 8). As the direction of misclassification between the self-reported LPG consumption variables was similar across all three communities (Supplementary Fig. 3) (consumption using self-reported number of annual refills was higher than that calculated via the average cylinder lifetime among $75 \%$ of households), we expect that this misclassification was non-differential and therefore biased towards a null finding. We recommend that future studies that collect self-reported data on LPG consumption phrase survey questions in terms of 'average cylinder lifetime' in addition to number of annual cylinder refills to help protect against overreporting. As other studies have found low agreement between self-reported and objective measures ${ }^{54}$, we further recommend that the absolute measures of LPG consumption and cylinder refill costs reported in this study be interpreted with caution.

This study examined household energy decisions in a unique peri-urban context. As the extent of fuel stacking and availability of free biomass typically varies between rural and peri-urban households $^{31,43,57}$, and research has shown differences in LPG consumption in urban, rural and peri-urban settings ${ }^{44,45,53}$, the study results may not hold outside peri-urban communities. We further point out that primary cooking fuels can vary seasonally due to fluctuations in income or changes in cooking needs ${ }^{24}$. As cooking patterns can also fluctuate over the course of the year, the per capita LPG consumption rates derived from this cross-sectional study may not reflect long-term LPG usage. Further, as household energy decisions are complex, additional participatory research methods (for example, focus group discussions and visual participatory methods) are important to place the findings from the modelling in context and understand the perspectives of individuals who use the cooking fuels ${ }^{60}$. These qualitative research methods have been employed by CLEAN-Air(Africa) and the results will be shared in the future ${ }^{36}$.

\section{Conclusions}

This study presents empirical evidence of the critical role of supply-side determinants in increasing LPG consumption among peri-urban households in three SSA countries, even at small scales (for example, 10 minute travel intervals). Although a lower cylinder price of an LPG refill will undoubtedly increase its consumption, other amenable factors, such as shortening the distance to LPG retail points and improving access to multiburner stoves, represent short-term, palpable interventions that may be crucial to minimize fuel stacking and accelerate growth of the clean cooking market in peri-urban SSA.

\section{Methods}

Study setting and population. This study, conducted as part of the CLEAN-Air(Africa) programme ${ }^{36}$, received ethical approval from the University of Liverpool, United Kingdom, and local ethics committees in each study country: Central Regional Ethics Committee for Human Health Research (Cameroon), Institutional Research and Ethics Committee for Moi Teaching and Referral Hospital and Moi University (Kenya) and Kintampo Health Research Centre (Ghana). Informed written consent was obtained from all the participants prior to conducting the study. No compensation was provided to participants for agreeing 
to take part in the survey.

The CLEAN-Air(Africa) programme consisted of applied research and capacity building within peri-urban communities in three SSA countries: Mbalmayo, an agricultural town in central Cameroon with 60,000 residents that is an hour drive away from Yaoundé, the country's capital; Obuasi, a gold-mining community in southern Ashanti, Ghana, with a population of almost 200,000 that is an hour drive away from Kumasi (capital city of the Ashanti region); Eldoret, a town surrounded by agricultural land, located at an elevation of over 2,000 $\mathrm{m}$ in Western Kenya with a population of nearly 500,000 and currently the fastest growing town in Kenya according to the 2019 National Census. In each location, approximately 2,000 households were surveyed to ensure a sufficient sampling frame for comparative research between households cooking primarily with LPG and exclusively with polluting fuels in later phases of CLEAN-Air(Africa). Across all three study settings, a total of 6,424 households were asked to participate and $97 \%(n=6,245)$ consented. Participants that did not typically cook at home and ate their meals primarily at local eateries $(n=607,9 \%)$ were excluded, left a final study sample of 5,638 households.

Survey data collection platforms. Survey data were collected using secure web technology (Mobenzi Researcher in Cameroon and Kenya, and REDCap (Research Electronic Data Capture) in Ghana) from April to November 2019. Mobenzi is a data collection software system (data encrypted at source) whereby data from predefined surveys are collected by smartphone application and automatically uploaded via the phone's SIM (subscriber identification module) card and synced to the Mobenzi cloud (or when the phone is connected to a wireless network if there is no mobile signal $)^{61}$. REDCap is an encrypted web application to create and manage online surveys and databases; data are wirelessly imported directly to the database servers. Completion took approximately $20 \mathrm{~min}$. Owing to a switch from random to purposive sampling (by primary cooking fuel type) midway through the data collection in Eldoret (to ensure a sufficient sample of households using LPG for future phases of CLEAN-Air(Africa) research), population-based results are reported among a subset of 757 households for this location.

Dependent variables. The first outcome of interest was the use of LPG as a primary or secondary cooking fuel among all households that cooked with LPG at the time of the survey administration. Participants' primary cooking fuel was determined from the question 'What does this household use for cooking most of the time, including cooking food, making tea/coffee, boiling drinking water?'. Use of secondary cooking fuels was gauged from the question 'What other fuels and energy sources does this household use for cooking food, making tea/coffee, boiling drinking water and/or starting the fire?'. No distinction was made between secondary and tertiary cooking fuels among households that reported three or more cooking fuels; hence, all the fuels that were not stated as the main cooking fuel are considered secondary fuels in this analysis.

The second outcome of interest was annual per capita consumption of LPG among all the households that used LPG as a primary or secondary fuel. The annual per capita LPG consumption $\left(\mathrm{kg} \mathrm{capita}^{-1} \mathrm{yr}^{-1}\right)$ was estimated in two ways: (1) multiplying the self-reported LPG cylinder size by the number of annual refills and dividing by the number of household members and (2) dividing 12 months by the self-reported average duration (months) of a cylinder refill to obtain a second estimate of the self-reported number of annual refills and multiplying that quantity by cylinder size and dividing by the number of household members. Sensitivity analyses examined the effects of using both metrics as the outcome on modelling results. The distribution of annual per capita LPG consumption was right-skewed so data were natural log-transformed before modelling.

Statistical analysis. A two multilevel (households nested within communities) models were built: (1) use of LPG as a primary or secondary cooking fuel (logistic regression) and (2) self-reported quantity (kg) of LPG consumed per capita (log-linear regression). Variables were considered for both models based on a priori knowledge or previous literature, which suggested a potential association with household cooking fuel decisions. Individual variables were added or removed from the models based on their significance in the model and their effect on the coefficient of determination $\left(R^{2}\right)$ when added to the model, with consideration given to selection of parsimonious models. The list of variables included in the modelling are described in Supplementary Table 1. Results from logistic regression modelling are depicted as the average-adjusted predicted probability of using LPG as a primary cooking fuel. Findings from log-linear regression are portrayed as the average-adjusted annual LPG per capita consumption $\left(\mathrm{kg} \mathrm{capita}^{-1} \mathrm{yr}^{-1}\right)$ :

- Model 1: LPG cooking fuel (primary/secondary) $)_{i k}=\beta_{0}+\beta_{1}+b_{i}+e_{i k}(\operatorname{logistic}$ regression).

- $\quad$ Model 2: $\ln \left(\mathrm{kg} \mathrm{LPG} \mathrm{capita} \mathrm{k}^{-1} \mathrm{yr}^{-1}\right)_{i k}=\beta_{0}+\beta_{1}+b_{i}+e_{i k}$ (log-linear regression).

In Model 1, LPG cooking fuel (primary/secondary) ${ }_{i k}$ represents whether the $k$ th participant in community $i$ uses LPG as a primary or secondary cooking fuel. In Model 2, $\ln \left(\mathrm{kg} \mathrm{LPG} \mathrm{capita}^{-1} \mathrm{yr}^{-1}\right)_{i k}$ represents the natural log transformed annual per capita consumption of the $k$ th participant in community $i$. In both models, $\beta_{0}$ is the overall intercept, $\beta_{1}$ represents fixed effects, $b_{i}$ is the community-level random effect and $e_{i k}$ is the residual error.
Model fit was assessed via a combination of the $R^{2}$, Akaike information criterion and tenfold cross-validation (training and test datasets are split at the community level to ensure a more accurate evaluation of the model performance). The cross-validated $R^{2}$ is reported for the linear model ${ }^{62}$ and the area under the receiver operating characteristic curve is reported for the logistic model ${ }^{63}$. All the data analysis was conducted in $\mathrm{R}$ (version 3.5 .1$)^{64}$.

Explanatory variables. Household SES was assessed via household income and highest level of education among household members, which have been shown to be associated with greater use of clean cooking fuels ${ }^{21-23}$. Additionally, a principal components analysis was run on household assets across all three communities combined to generate a measure of household SES additional to household income and education ${ }^{65}$. The first principal component was grouped into quartiles and tested as a predictor in both regression models. The full list of household assets included in the principal components analysis is provided in Supplementary Table 1.

Supply-side characteristics included participants' perceptions about the availability of LPG at the retail point. Participants were asked how frequently LPG was unavailable at the retailer and could select from preset categories of (1) always available, (2) 4 times per year, (3) $4-12$ times per year or (4) >12 times per year. Participants were asked to provide the current cost of the LPG cylinder they purchase. The cost provided by the participant was divided by the cylinder size used by the household to generate the per kilogram price. All per capita fuel prices in each country were converted to US dollars and grouped into quartiles (see Supplementary Table 1 for the price cutoff points). Participants were asked about the typical amount of time required to reach the LPG retailer (one-way) using their usual mode of transportation. Travel times were grouped into 10 min intervals. Participants were also asked about their usual mode of transport to obtain the LPG cylinder refill: (1) walking, (2) motorbike, (3) public transportation, (4) car or (5) home delivery. Lastly, a binary variable of whether the participant currently pays for all their cooking fuels or gathers biomass locally for free was considered in both models.

Cooking behaviours were characterized by the self-reported frequency of LPG use during the previous week (that is 1-7 days) and the number of years the participant has been cooking with LPG. Whether or not the participant used LPG exclusively or stacked with other fuels was included in the model of LPG annual per capita consumption. The number of LPG stove burners was also asked to determine if this may increase usage. Household demographics were accounted for by quantifying the number of individuals who lived in the household and the number of children under five years old. Marital status and sex of the fuel decision maker were also considered in all regression models.

Data limitations. The two outcomes assessed in this study, using LPG as a primary or secondary fuel and kilograms of LPG consumed per capita per year, do not account for the extent of polluting fuel displacement, and therefore may not directly correlate with health or climate benefits. Further studies that quantify LPG consumption alongside the quantity of polluting fuels used can improve how LPG supply-related factors contribute to potential health gains among households.

Additionally, self-reported quantitative data, which include LPG cylinder refill costs and transportation costs, may partially reflect user perceptions and thus be higher or lower than the actual value in some instances. To minimize the potential for bias to impact the results, quantitative predictors were grouped into quartiles before being added to the regression models (Supplementary Table 1); the resulting monotonically decreasing relationship between increasing transportation and the fuel cost 'quartile' and lower LPG per capita consumption is therefore likely to be a true association.

Despite these limitations, this modelling study incorporates a diverse set of household energy supply and demand-related variables and identifies new-found factors (for example, number of stove burners) that influence cooking fuel decisions. Thus, the findings highlight that the ability of LPG to meet households' cooking needs (for example, the ability to cook multiple dishes simultaneously on multiple burners) may increase its consumption. End-user preferences should therefore be factored into future clean-energy scale-up efforts, particularly as larger family sizes in SSA typically have a much lower LPG consumption.

As all data in this study were self-reported, information on availability of LPG at retailers and fuel prices may be skewed by participants' positive or negative views regarding LPG supply and cost. Future research that collects data on user perceptions on various aspects of cooking with and obtaining LPG cylinder refills, alongside objective supply-related measurements, is warranted. Nonetheless, the large sample size of this study is likely to minimize any meaningful effects of response bias on the statistically significant relationships found between several supply-side characteristics and LPG usage found in the modelling results.

Reporting Summary. Further information on research design is available in the Nature Research Reporting Summary linked to this article.

\section{Data availability}

Data is still under use by CLEAN-Air(Africa) for future work, but can be made available to researchers upon reasonable request directed to the corresponding author. 


\section{Code availability}

The source code used in this study can be accessed through Figshare at https://doi. org/10.6084/m9.figshare.16699492.

Received: 23 January 2021; Accepted: 5 October 2021; Published online: 18 November 2021

\section{References}

1. State of Global Air 2020 (Health Effects Institute, 2020).

2. Bruce, N. et al. WHO indoor air quality guidelines on household fuel combustion: strategy implications of new evidence on interventions and exposure-risk functions. Atmos. Environ. 106, 451-457 (2015).

3. Po, J. Y., FitzGerald, J. M. \& Carlsten, C. Respiratory disease associated with solid biomass fuel exposure in rural women and children: systematic review and meta-analysis. Thorax 66, 232-239 (2011).

4. Li, L. et al. Indoor air pollution from solid fuels and hypertension: a systematic review and meta-analysis. Environ. Pollut. 259, 113914 (2020).

5. Yu, K. et al. Association of solid fuel use with risk of cardiovascular and all-cause mortality in rural China. J. Am. Med. Assoc. 319, 1351-1361 (2018).

6. Sumpter, C. \& Chandramohan, D. Systematic review and meta-analysis of the associations between indoor air pollution and tuberculosis. Tropical Med. Int. Health 18, 101-108 (2013).

7. Shupler, M. et al. Household and personal air pollution exposure measurements from 120 communities in eight countries: results from the PURE-AIR study. Lancet Planet. Health 4, e451-e462 (2020).

8. Quinn, A. K. et al. Association of carbon monoxide exposure with blood pressure among pregnant women in rural Ghana: Evidence from GRAPHS. Int. J. Hyg. Environ. Health 219, 176-183 (2016).

9. Agrawal, S. \& Yamamoto, S. Effect of indoor air pollution from biomass and solid fuel combustion on symptoms of preeclampsia/eclampsia in Indian women. Indoor Air 25, 341-352 (2015)

10. Baumgartner, J. et al. Highway proximity and black carbon from cookstoves as a risk factor for higher blood pressure in rural China. Proc. Natl Acad. Sci. USA 111, 13229-13234 (2014).

11. Bailis, R., Drigo, R., Ghilardi, A. \& Masera, O. The carbon footprint of traditional woodfuels. Nat. Clim. Change 5, 266-272 (2015).

12. Bond, T. C. \& Sun, H. Can reducing black carbon emissions counteract global warming? Environ. Sci. Technol. 39, 5921-5926 (2005).

13. Kumar, P. \& Mehta, S. Poverty, gender, and empowerment in sustained adoption of cleaner cooking systems: making the case for refined measurement. Energy Res. Soc. Sci. 19, 48-52 (2016).

14. Burning Opportunity: Clean Household Energy for Health, Sustainable Development, and Wellbeing of Women and Children (WHO, 2016); http://www.who.int/indoorair/publications/burning-opportunities/en/

15. World Energy Outlook 2020 (International Energy Agency, 2020); https://www.iea.org/reports/world-energy-outlook-2020

16. Bruce N. G., Aunan K., Rehfuess E. A. Liquefied Petroleum Gas as a Clean Cooking Fuel for Developing Countries: Implications for Climate, Forests, and Affordability (KfW Development Bank, 2017); https://staticl.squarespace.com/ static/53856elee4b00c6f1fclf602/t/5b16ec08352f538a85f57d7c/15282288 77332/2017_Liquid-Petroleum-Clean-Cooking_KfW.pdf

17. Bruce, N. et al. The Government-led initiative for LPG scale-up in Cameroon: programme development and initial evaluation. Energy Sustain. Dev. 46, 103-110 (2018).

18. Van Leeuwen V., Evans A. \& Hyseni B. Increasing the Use of Liquefied Petroleum Gas in Cooking in Developing Countries Report no. 114846 (The World Bank, 2017); http://documents.worldbank.org/curated/en/70732149 4347176314/Increasing-the-use-of-liquefied-petroleum-gas-in-cookingin-developing-countries

19. Shen, G. et al. Evaluating the performance of household liquefied petroleum gas cookstoves. Environ. Sci. Technol. 52, 904-915 (2018).

20. Simkovich, S. M. et al. A systematic review to evaluate the association between clean cooking technologies and time use in low- and middle-income countries. Int. J. Environ. Res. Public Health 16, 2277 (2019).

21. Heltberg, R. Fuel switching: evidence from eight developing countries. Energy Econ. 26, 869-887 (2004).

22. Leach, G. The energy transition. Energy Policy 20, 116-123 (1992).

23. Masera, O. R., Saatkamp, B. D. \& Kammen, D. M. From linear fuel switching to multiple cooking strategies: a critique and alternative to the energy ladder model. World Dev. 28, 2083-2103 (2000).

24. Shankar, A. V. et al. Everybody stacks: lessons from household energy case studies to inform design principles for clean energy transitions. Energy Policy 141, 111468 (2020).

25. Mani, S., Jain, A., Tripathi, S. \& Gould, C. F. The drivers of sustained use of liquified petroleum gas in India. Nat. Energy 5, 450-457 (2020).

26. Gould, C. F., Hou, X., Richmond, J., Sharma, A. \& Urpelainen, J. Jointly modeling the adoption and use of clean cooking fuels in rural India. Environ. Res. Commun. 2, 085004 (2020).
27. Puzzolo, E., Pope, D., Stanistreet, D., Rehfuess, E. A. \& Bruce, N. G. Clean fuels for resource-poor settings: a systematic review of barriers and enablers to adoption and sustained use. Environ. Res. 146, 218-234 (2016).

28. Lewis, J. J. \& Pattanayak, S. K. Who adopts improved fuels and cookstoves? A systematic review. Environ. Health Perspect. 120, 637-645 (2012).

29. Puzzolo, E. et al. Supply considerations for scaling up clean cooking fuels for household energy in low- and middle-income countries. GeoHealth 3, 370-390 (2019).

30. Pope, D. et al. Household determinants of liquified petroleum gas (LPG) as a cooking fuel in SW Cameroon. EcoHealth 15, 729-743 (2018).

31. Stanistreet, D. et al. Barriers and facilitators to the adoption and sustained use of cleaner fuels in Southwest Cameroon: situating 'lay' knowledge within evidence-based policy and practice. Int. J. Environ. Res. Public Health 16, 4702 (2019).

32. Choumert-Nkolo, J., Combes Motel, P. \& Le Roux, L. Stacking up the ladder: a panel data analysis of Tanzanian household energy choices. World Dev. 115 222-235 (2019)

33. Alem, Y., Beyene, A. D., Köhlin, G. \& Mekonnen, A. Modeling household cooking fuel choice: a panel multinomial logit approach. Energy Econ. 59, 129-137 (2016).

34. Rehfuess, E. A., Briggs, D. J., Joffe, M. \& Best, N. Bayesian modelling of household solid fuel use: insights towards designing effective interventions to promote fuel switching in Africa. Environ. Res. 110, 725-732 (2010).

35. Shupler, M. et al. Household, community, sub-national and country-level predictors of primary cooking fuel switching in nine countries from the PURE study. Environ. Res. Lett. 14, 085006 (2019).

36. Puzzolo, E. et al. Clean energy access for the prevention of non-communicable disease in Africa: the NIHR CLEAN-Air (Africa) Global Health Research Group. Environ. Epidemiol. 3, 319 (2019).

37. Harmonized Survey Questions for Monitoring Household Energy Use and SDG Indicators 7.1.1 and 7.1.2 (WHO, 2018); https://www.who.int/airpollution/ household/1_Harmonized_household_energy_survey_questions-list_format_ final_Nov2019.pdf?ua=1

38. Campbell, C. A. et al. Investigating cooking activity patterns and perceptions of air quality interventions among women in urban Rwanda. Int. J. Environ. Res. Public Health 18, 5984 (2021).

39. Shupler, M. et al. Pay-as-you-go LPG supports sustainable clean cooking in Kenyan informal urban settlement, including during a period of COVID-19 lockdown. Appl. Energy 292(116769).

40. Ochieng, C. A., Zhang, Y., Nyabwa, J. K., Otieno, D. I. \& Spillane, C. Household perspectives on cookstove and fuel stacking: a qualitative study in urban and rural Kenya. Energy Sustain. Dev. 59, 151-159 (2020).

41. Asante, K. P. et al. Ghana's rural liquefied petroleum gas program scale up: a case study. Energy Sustain. Dev. 46, 94-102 (2018)

42. Rahut, D. B., Behera, B. \& Ali, A. Factors determining household use of clean and renewable energy sources for lighting in Sub-Saharan Africa. Renew. Sustain. Energy Rev. 72, 661-672 (2017).

43. Wiedinmyer, C. et al. Rural-urban differences in cooking practices and exposures in Northern Ghana. Environ. Res. Lett. 12, 065009 (2017).

44. National Feasibility Study: LPG for Clean Cooking in Kenya (The Global LPG Partnership, 2018)

45. National Feasibility Assessment: LPG for Clean Cooking in Ghana (The Global LPG Partnership, 2018).

46. Aung, T. et al. Energy access and the ultra-poor: do unconditional social cash transfers close the energy access gap in Malawi? Energy Sustain. Dev. 60, 102-112 (2021)

47. Hsu, E. et al. Microfinance for clean cooking: what lessons can be learned for scaling up LPG adoption in Kenya through managed loans? Energy Policy 154, 112263 (2021).

48. Kar, A., Pachauri, S., Bailis, R. \& Zerriffi, H. Using sales data to assess cooking gas adoption and the impact of India's Ujjwala programme in rural Karnataka. Nat. Energy 4, 806-814 (2019).

49. Ngui, D., Mutua, J., Osiolo, H. \& Aligula, E. Household energy demand in Kenya: an application of the linear approximate almost ideal demand system (LA-AIDS). Energy Policy 39, 7084-7094 (2011).

50. van der Kroon, B., Brouwer, R. \& van Beukering, P. J. H. The energy ladder: theoretical myth or empirical truth? Results from a meta-analysis. Renew. Sustain. Energy Rev. 20(C), 504-513 (2013).

51. Bisaga, I. \& Parikh, P. To climb or not to climb? Investigating energy use behaviour among Solar Home System adopters through energy ladder and social practice lens. Energy Res. Soc. Sci. 44, 293-303 (2018).

52. Neto-Bradley, A. P., Choudhary, R. \& Bazaz, A. Slipping through the net: can data science approaches help target clean cooking policy interventions? Energy Policy 144, 111650 (2020).

53. National Feasibility Assessment: LPG for Clean Cooking in Cameroon (The Global LPG Partnership, 2019).

54. Kar, A., Brauer, M., Bailis, R. \& Zerriffi, H. The risk of survey bias in self-reports vs. actual consumption of clean cooking fuels. World Dev. Perspect. 18, 100199 (2020). 
55. 2019 Kenya Population and Housing Census (Kenya National Bureau of Statistics, 2019); https://open.africa/dataset/2019-kenya-population-andhousing-census

56. Scaling LPG for Cooking in Developing Markets: Insights from Tanzania (Clean Cooking Alliance. 2019); https://www.enea-consulting.com/en/scaling-lpgfor-cooking-in-developing-markets

57. Jagger, P. \& Perez-Heydrich, C. Land use and household energy dynamics in Malawi. Environ. Res. Lett. 11, 125004 (2016)

58. Carrión, D. et al. Using longitudinal survey and sensor data to understand the social and ecological determinants of clean fuels use and discontinuance in rural Ghana. Environ. Res. Commun. 2, 095003 (2020).

59. Carter, E. et al. Household transitions to clean energy in a multiprovincial cohort study in China. Nat. Sustainability. 3, 42-50 (2020).

60. Ronzi, S. et al. Using photovoice methods as a community-based participatory research tool to advance uptake of clean cooking and improve health: the LPG adoption in Cameroon evaluation studies. Soc. Sci. Med 228, 30-40 (2019).

61. van Heerden, A., Norris, S., Tollman, S., Richter, L. \& Rotheram-Borus, M. J. Collecting maternal health information from HIV-positive pregnant women using mobile phone-assisted face-to-face interviews in Southern Africa. J. Med. Internet Res. 15, e116 (2013).

62. Yuchi, W. et al. Evaluation of random forest regression and multiple linear regression for predicting indoor fine particulate matter concentrations in a highly polluted city. Environ. Pollut. 245, 746-753 (2019).

63. Maroco, J. et al. Data mining methods in the prediction of dementia: a real-data comparison of the accuracy, sensitivity and specificity of linear discriminant analysis, logistic regression, neural networks, support vector machines, classification trees and random forests. BMC Res. Notes 4, 299 (2011).

64. R Core Team R: a Language and Environment for Statistical Computing (R Foundation for Statistical Computing, 2017). http://www.R-project.org/

65. Vyas, S. \& Kumaranayake, L. Constructing socio-economic status indices: how to use principal components analysis. Health Policy Plan 21 , 459-468 (2006).

\section{Acknowledgements}

We express gratitude to the field staff at each of the three research institutions (Douala General Hospital, Moi University and Kintampo Health Research Centre) for their dedication and efficient effort in administering thousands of household surveys in a timely manner. This research was funded as part of the CLEAN-Air(Africa) Global Health Research Group by the National Institute for Health Research (NIHR) (ref. 17/63/155) (grant awarded to D.P.) using UK aid from the UK government to support global health research. All the authors are members of the CLEANAir(Africa) programme.

\section{Author contributions}

M.S. assisted with the survey design, supervised the data collection, managed, cleaned and analysed all the data, and wrote the first and final drafts of the paper. E.P. and D.P. designed and supervised the conduct of the CLEAN-Air(Africa) study and supervised the interpretation of the data. E.N. assisted with data cleaning, management and interpretation. M.B., E.B., J.M., E.S., T.T. and J.S. led the data collection and study logistics in their respective study countries. D.M., B.M. K.P.A. and R.Q. designed and supervised the conduct of the CLEAN-Air(Africa) study, directed the study implementation and supervised the data collection in their respective countries. D.P., E.P., R.A.d.C., M.T. and S.A.-E. helped oversee the data management in the CLEAN-Air(Africa) study. All the co-authors reviewed and commented on the final manuscript.

\section{Competing interests}

The authors declare no competing interests.

\section{Additional information}

Supplementary information The online version contains supplementary material available at https://doi.org/10.1038/s41560-021-00933-3.

Correspondence and requests for materials should be addressed to Matthew Shupler.

Peer review information Nature Energy thanks Abhishek Kar, Pamela Jagger and Caroline Ochieng for their contribution to the peer review of this work.

Reprints and permissions information is available at www.nature.com/reprints. Publisher's note Springer Nature remains neutral with regard to jurisdictional claims in published maps and institutional affiliations.

\section{(c) (i) Open Access This article is licensed under a Creative Commons}

Attribution 4.0 International License, which permits use, sharing, adaptation, distribution and reproduction in any medium or format, as long as you give appropriate credit to the original author(s) and the source, provide a link to the Creative Commons license, and indicate if changes were made. The images or other third party material in this article are included in the article's Creative Commons license, unless indicated otherwise in a credit line to the material. If material is not included in the article's Creative Commons license and your intended use is not permitted by statutory regulation or exceeds the permitted use, you will need to obtain permission directly from the copyright holder. To view a copy of this license, visit http://creativecommons. org/licenses/by/4.0/.

(C) The Author(s) 2021 


\section{Reporting Summary}

Nature Research wishes to improve the reproducibility of the work that we publish. This form provides structure for consistency and transparency in reporting. For further information on Nature Research policies, see our Editorial Policies and the Editorial Policy Checklist.

\section{Statistics}

For all statistical analyses, confirm that the following items are present in the figure legend, table legend, main text, or Methods section.

$\mathrm{n} / \mathrm{a}$ Confirmed

$\bigotimes$ The exact sample size $(n)$ for each experimental group/condition, given as a discrete number and unit of measurement

$\square$ A statement on whether measurements were taken from distinct samples or whether the same sample was measured repeatedly

The statistical test(s) used AND whether they are one- or two-sided

Only common tests should be described solely by name; describe more complex techniques in the Methods section.

$\searrow$ A description of all covariates tested

$\square$ \ A description of any assumptions or corrections, such as tests of normality and adjustment for multiple comparisons

$\square$ A full description of the statistical parameters including central tendency (e.g. means) or other basic estimates (e.g. regression coefficient)

AND variation (e.g. standard deviation) or associated estimates of uncertainty (e.g. confidence intervals)

$\varnothing$ For null hypothesis testing, the test statistic (e.g. $F, t, r$ ) with confidence intervals, effect sizes, degrees of freedom and $P$ value noted

$\triangle$ Give $P$ values as exact values whenever suitable.

Х $\square$ For Bayesian analysis, information on the choice of priors and Markov chain Monte Carlo settings

$\square$ \ For hierarchical and complex designs, identification of the appropriate level for tests and full reporting of outcomes

Х $\square$ Estimates of effect sizes (e.g. Cohen's $d$, Pearson's $r$ ), indicating how they were calculated

Our web collection on statistics for biologists contains articles on many of the points above.

\section{Software and code}

Policy information about availability of computer code

Data collection Surveys were administered to 6,424 participants in 2019 via mobile phones or tablets using secure data collection technology. Mobenzi Reseacher was used in Cameroon and Kenya, and Research Electronic Data Capture (REDCap) was used in Ghana. Using both platforms, data was converted into .csv files and downloaded and shared securely.

Data analysis All data analysis and figure generation was conducted using R version 3.5.1

For manuscripts utilizing custom algorithms or software that are central to the research but not yet described in published literature, software must be made available to editors and reviewers. We strongly encourage code deposition in a community repository (e.g. GitHub). See the Nature Research guidelines for submitting code \& software for further information.

\section{Data}

Policy information about availability of data

All manuscripts must include a data availability statement. This statement should provide the following information, where applicable:

- Accession codes, unique identifiers, or web links for publicly available datasets

- A list of figures that have associated raw data

- A description of any restrictions on data availability

Data is still under use by CLEAN-Air(Africa) for future work but can be made available to researchers upon reasonable request directed to the corresponding author. 
Please select the one below that is the best fit for your research. If you are not sure, read the appropriate sections before making your selection.

Life sciences $\quad$ Behavioural \& social sciences $\square$ Ecological, evolutionary \& environmental sciences

For a reference copy of the document with all sections, see nature.com/documents/nr-reporting-summary-flat.pdf

\section{Behavioural \& social sciences study design}

All studies must disclose on these points even when the disclosure is negative.

Study description

Research sample

Sampling strategy

Data collection

Timing

Data exclusions

Non-participation

Randomization
A cross-sectional, quantitative analysis was conducted using multilevel log-linear (natural log-transformed kg/capita/year as outcome variable) and logistic (use of LPG as a primary or secondary cooking fuel as outcome variable) regression to assess patterns of LPG usage.

The sample is peri-urban households from three communities across Sub-Saharan Africa - Mbalmayo, Cameroon; Obuasi, Ghana and Eldoret, Kenya. The samples in each of the three study settings are representative of the communities. However, in Eldoret, Kenya, random sampling was conducted among only a subset of households, owing to a lower-than-expected prevalence of LPG usage in the community. As a result, the field team switched to purposive sampling after recruitment of 757 of 2,000 households in the study location to ensure more households cooking with LPG were included. The three study countries in Sub-Saharan Africa were selected to participate because national governments in each country have recently established policies for rapid expansion of use of LPG for cooking.

Random sampling was conducted in various communities within each of the three peri-urban towns to ensure a representative sample. A target sample of 2,000 households in each setting (6,000 households total) was established for the purposes of ensuring a sufficient number of households using LPG for cooking would be available for follow up in subsequent phases of data collection in the CLEAN Air(Africa) study.

Data were collected via smartphones (Kenya and Cameroon) or tablets (Ghana). A secure mobile application (Mobenzi in Kenya and Cameroon; RedCap in Ghana) was used to conduct the surveys. The surveys were designed by investigators at the University of Liverpool with local input from researchers at each of the institutions. A team of field workers from institutions in each of the study settings underwent training in the survey questions and the surveys were piloted prior to use. The fieldworkers administered the survey to the main cook of the household.

Data was collected from March-April 2019 in Mbalmayo, Cameroon, from May to November 2019 in Eldoret, Kenya and from July to September 2019 in Obuasi, Ghana.

Participants that indicated not cooking at home ( $n=607)$, representing $9 \%$ of the study sample ( $n=6,424$ participants), were excluded, as this analysis was examining the impact of various factors on cooking fuel consumption. The final analytic sample included 5,638 participants.

A total of 177 participants ( $3 \%$ of total sample of 6,424 participants) refused to take part in the survey, mostly due to a lack of interest in participating.

Not applicable.

\section{Reporting for specific materials, systems and methods}

We require information from authors about some types of materials, experimental systems and methods used in many studies. Here, indicate whether each material, system or method listed is relevant to your study. If you are not sure if a list item applies to your research, read the appropriate section before selecting a response.

Materials \& experimental systems

$\mathrm{n} / \mathrm{a}$ Involved in the study

$\bigotimes \square$ Antibodies

Х $\square$ Eukaryotic cell lines

Х $\square$ Palaeontology and archaeology

\ $\square$ Animals and other organisms

$\square \bigotimes$ Human research participants

$\square$ Clinical data

$\bigotimes \square$ Dual use research of concern

\section{Methods}

$\mathrm{n} / \mathrm{a}$ Involved in the study

Х $\square$ ChIP-seq

Х $\square$ Flow cytometry

Х $\square$ MRI-based neuroimaging 
Policy information about studies involving human research participants

Population characteristics

Recruitment

Ethics oversight
See above.

Field staff conducted door-to-door sampling at randomly selected communities in each location. Participants were asked if they would be willing to participate in a 20-minute survey regarding their cooking behaviours.

Ethical approval was obtained from the University of Liverpool, United Kingdom and local ethics committees in each study country: Central Regional Ethics Committee for Human Health Research (Cameroon), Instiutional Research and Ethics Committee for Moi Teaching and Referral Hospital and Moi University (Kenya) and Kintampo Health Research Centre (Ghana).

Note that full information on the approval of the study protocol must also be provided in the manuscript. 